\title{
Incorporating diffuse radiation into a light use efficiency and evapotranspiration model: An 11-year study in a high latitude deciduous forest
}

Wang, Sheng; Ibrom, Andreas; Bauer-Gottwein, Peter; Garcia, Monica

Published in:

Agricultural and Forest Meteorology

Link to article, DOI:

10.1016/j.agrformet.2017.10.023

Publication date:

2018

Document Version

Peer reviewed version

Link back to DTU Orbit

Citation (APA):

Wang, S., Ibrom, A., Bauer-Gottwein, P., \& Garcia, M. (2018). Incorporating diffuse radiation into a light use efficiency and evapotranspiration model: An 11-year study in a high latitude deciduous forest. Agricultural and Forest Meteorology, 248, 479-493. https://doi.org/10.1016/j.agrformet.2017.10.023

\section{General rights}

Copyright and moral rights for the publications made accessible in the public portal are retained by the authors and/or other copyright owners and it is a condition of accessing publications that users recognise and abide by the legal requirements associated with these rights.

- Users may download and print one copy of any publication from the public portal for the purpose of private study or research.

- You may not further distribute the material or use it for any profit-making activity or commercial gain

- You may freely distribute the URL identifying the publication in the public portal 
1 Incorporating diffuse radiation into a light use efficiency and evapotranspiration model:

2 an 11-year study in a high latitude deciduous forest

3 Sheng Wang ${ }^{\mathrm{a} *}$, Andreas Ibrom ${ }^{\mathrm{a}}$, Peter Bauer-Gottwein ${ }^{\mathrm{a}}$, Monica Garcia ${ }^{\mathrm{a}, \mathrm{b}}$

4 a. Department of Environmental Engineering, Technical University of Denmark, 2800 Kgs. Lyngby, Denmark; b.

5 International Research Institute for Climate and Society, The Earth Institute, Columbia University, Palisades,

6 NY (USA)

$7 \quad *$ corresponding author: swan@env.dtu.dk

\section{Abstract:}

9 The fraction of diffuse photosynthetic active radiation (PAR) reaching the land surface is one of the biophysical factors regulating carbon and water exchange between ecosystems and the atmosphere. This is especially relevant for high latitude ecosystems, where cloudy days are prevalent. Without considering impacts of diffuse PAR, traditional 'top-down' models of ecosystem gross primary productivity (GPP) and evapotranspiration (ET), which use satellite remote sensing observations, tend to be biased towards clear sky conditions. Thus, this study incorporated a cloudiness index (CI), an index for the fraction of diffuse PAR, into a joint 'top-down' model that uses the same set of biophysical constraints to simulate GPP and ET for a high latitude temperate deciduous forest. To quantify the diffuse PAR effects, CI along with other environmental variables derived from an elevenyear eddy covariance data set were used to statistically explore the independent and joint effects of diffuse PAR on GPP, ET, incident light use efficiency (LUE), evaporative fraction (EF) and ecosystem water use efficiency (WUE). The independent and joint effects of CI were compared from global sensitivity analysis of the 'top-down' models. Results indicate that for independent effects, CI increased GPP, LUE, ET, EF and WUE, but analysis of joint effects shows that as CI mainly interacted with the radiation intercepted in the canopy (PAR, net radiation and leaf area index) to influence GPP, ET and WUE. Moreover, Ta and vapor pressure deficit played a major role for the joint influence of CI on LUE and EF. We quantified that CI contributes $11.88 \%, 3.04 \%$ and $7.78 \%$ to the total variation of GPP, ET and transpiration in the growing season from May to October, respectively. As the influence of CI on GPP is larger than that on ET, this leads to an increase in WUE. Joint GPP and ET model results showed that when including CI, the root mean square errors (RMSE) of daily GPP decreased from 1.64 to $1.45 \mathrm{~g} \cdot \mathrm{C} \cdot \mathrm{m}^{-2} \cdot \mathrm{d}^{-1}\left(11.68 \%\right.$ reduction) and ET from 15.79 to $14.50 \mathrm{~W} \cdot \mathrm{m}^{-2}$ (8.16\% reduction). Due to the interaction of diffuse PAR with plant canopies, the largest model improvements using CI for GPP and ET occurred during the growing season and for the transpiration component, as suggested by comparisons to sap flow measurements. Furthermore, our study suggests a potential biophysical mechanism, not considered in other studies: due to the increased longwave emission from clouds, surface temperature gets higher and closer to optimum, boosting GPP and transpiration in the temperature-limited high latitude ecosystem.

Key words: diffuse PAR fraction; eddy covariance; gross primary production; evapotranspiration; 'top-down' models; light use efficiency model; Priestley-Taylor Jet Propulsion Laboratory evapotranspiration model 


\section{Table of abbreviations and symbols:}

\section{Latin alphabet}

38 - CI: cloudiness index (dimensionless)

39 - EF: evaporative fraction (dimensionless)

40 - ET: evapotranspiration $\left(\mathrm{mm} \cdot \mathrm{d}^{-1}\right)$

41 - $f_{\text {APAR: }}$ fraction of absorbed PAR (dimensionless)

42 - $f_{c i}$ : cloudiness index constraint (dimensionless)

43 - $f_{\text {diff: }}$ fraction of diffuse PAR (dimensionless)

44 - $f_{g}$ : the green canopy fraction indicating the proportion of active canopy (dimensionless)

45 - $f_{M}$ : the plant moisture constraint (dimensionless)

- $f_{\mathrm{IPAR}}$ : fraction of intercepted PAR (dimensionless)

47 - $f_{T a}$ : the air temperature constraint reflecting the temperature limitation of photosynthesis (dimensionless)

48 - $f_{S W C}$ : the soil moisture constraint on photosynthesis (dimensionless)

- $f_{V P D}$ : the VPD constraint reflecting the stomatal response to the atmospheric water saturation deficit (dimensionless)

- G: Ground heat flux $\left(\mathrm{W} \cdot \mathrm{m}^{-2}\right)$

52 - GPP: gross primary productivity $\left(\mathrm{g} \cdot \mathrm{C} \cdot \mathrm{m}^{-2} \cdot \mathrm{d}^{-1}\right)$

53 - $\mathrm{k}_{\text {PAR: }}$ the extinction coefficients for PAR (0.5, dimensionless)

54 - $\mathrm{k}_{\mathrm{Rn}}$ : the extinction coefficients for $\mathrm{Rn}$ (0.6, dimensionless)

55 - LAI: leaf area index $\left(\mathrm{m}^{2} \cdot \mathrm{m}^{-2}\right)$

56 - LUE: incident light use efficiency $\left(\mathrm{g} \cdot \mathrm{C} \cdot \mathrm{MJ}^{-1}\right)$

57 - $\mathrm{LW}_{\text {in: }}$ incoming longwave radiation $\left(\mathrm{W} \cdot \mathrm{m}^{-2}\right)$

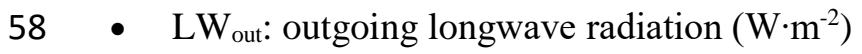

59 - NDVI: normalized difference vegetation index (dimensionless)

60 - PAR: photosynthetically active radiation $\left(\mathrm{MJ} \cdot \mathrm{m}^{-2} \cdot \mathrm{d}^{-1}\right)$

61 PARc: PAR intercepted by the canopy $\left(\mathrm{MJ} \cdot \mathrm{m}^{-2} \cdot \mathrm{d}^{-1}\right)$

62 - RH: the relative humidity (dimensionless)

63 - Rn: Net radiation $\left(\mathrm{W} \cdot \mathrm{m}^{-2}\right)$

64 Rnc: Net radiation intercepted by the canopy $\left(\mathrm{W} \cdot \mathrm{m}^{-2}\right)$

65 - Rns: Net radiation reaching to the soil $\left(\mathrm{W} \cdot \mathrm{m}^{-2}\right)$

66 - SWC: soil water content $\left(\mathrm{m}^{3} \cdot \mathrm{m}^{-3}\right)$

67 - $\mathrm{SW}_{\mathrm{in}}$ : incoming shortwave radiation $\left(\mathrm{W} \cdot \mathrm{m}^{-2}\right)$ 
- $\quad$ SZA: sun zenith angle (rad)

- $\quad$ Ta: air temperature $\left({ }^{\circ} \mathrm{C}\right)$

- $\quad$ Ts: surface temperature $\left({ }^{\circ} \mathrm{C}\right)$

- To: optimal air temperature for vegetation growth $\left({ }^{\circ} \mathrm{C}\right)$

- VPD: vapor pressure deficit (hPa)

- WUE: ecosystem water use efficiency $\left(\mathrm{g} \cdot \mathrm{C} \cdot \mathrm{kg}^{-1}\right)$

\section{Greek alphabet}

- $\quad \alpha$ : PT coefficient, an empirical ratio of potential evapotranspiration to equilibrium potential evapotranspiration (dimensionless)

- $\gamma$ : the psychrometric constant $\left(0.066 \mathrm{kPa}^{\circ}{ }^{\circ} \mathrm{C}^{-1}\right)$

- $\Delta$ : the slope of saturation-to-vapor pressure curve $\left(\mathrm{kPa} \cdot{ }^{\circ} \mathrm{C}^{-1}\right)$

- $\varepsilon$ : surface emissivity (dimensionless)

- $\varepsilon_{\text {max }}$ : maximum LUE $\left(\mathrm{g} \cdot \mathrm{C} \cdot \mathrm{m}^{-2} \cdot \mathrm{MJ}^{-1}\right)$

- $\lambda$ : latent heat of vaporization $\left(\mathrm{kJ}^{\mathrm{k}} \mathrm{kg}^{-1}\right)$

- $\lambda E T$ : latent heat flux of evapotranspiration $\left(\mathrm{W} \cdot \mathrm{m}^{-2}\right)$

- $\lambda E c$ : latent heat flux from transpiration $\left(\mathrm{W} \cdot \mathrm{m}^{-2}\right)$

- $\lambda$ Ei: latent heat flux from evaporation of intercepted water $\left(\mathrm{W} \cdot \mathrm{m}^{-2}\right)$

- $\quad \lambda$ Es: latent heat flux from evaporation of soil water $\left(\mathrm{W} \cdot \mathrm{m}^{-2}\right)$

- $\sigma$ : the Stefan-Boltzmann constant $\left(5.670367 \times 10^{-8} \mathrm{~kg} \cdot \mathrm{s}^{-3} \cdot \mathrm{K}^{-4}\right)$

\section{Introduction}

Quantifying land surface water and carbon fluxes is of critical importance for ecosystem and water resources management. The temporal dynamics of land surface carbon and water fluxes are controlled by the interplay of various biophysical factors, e.g. climate forcing (solar radiation, water vapor and temperature), atmospheric conditions $\left(\mathrm{CO}_{2}\right.$ concentration and nitrogen deposition) and biotic factors (leaf area index and plant functional types) (Ciais et al., 2005; Dunn et al., 2007; Wu et al., 2016). Among these biophysical factors, the fraction of diffuse photosynthetically active radiation (PAR), $f_{\text {diff }}$ (the ratio between diffuse and total PAR), has been highlighted to have strong implications for the global carbon cycle (Gu et al., 2003; Mercado et al., 2009). It could increase the efficiency of photosynthesis, which has been referred to the diffuse fertilization effect (Roderick et al., 2001; Kanniah et al., 2012). Further, predictions showed that, at the global scale, aerosols in the atmosphere would increase by 36\% in 2100 (Heald et al., 2008). Aerosols influence cloud formation and increase $f_{\text {diff }}$ in the atmosphere (Schiermeier, 2006). This is especially important for high latitude ecosystems, which are already exposed to a higher $f_{\text {diff }}$ due to low solar height and high frequency of overcast and cloudy conditions. 
With more uniform vertical distribution of incoming photosynthetic active radiation (PAR) under cloudy conditions, both observations and modeling studies have confirmed more active carbon assimilation rates (Gu et al., 2002; Lloyd et al., 2002; Steiner and Chameides, 2005; Ibrom et al. 2006, Urban et al., 2012). However, the gross primary productivity (GPP) enhancement depends on local environmental conditions and ecosystem types. Healy et al. (1998) reported that increasing $f_{\text {diff }}$ can increase the incident light use efficiency (LUE, defined as the ratio between GPP and incoming PAR). This increases crop yield by as much as $50 \%$ for maize, soybean and peanuts. According to observations from 10 temperate forest flux sites in USA, Cheng et al. (2015) found that $f_{\text {diff }}$ explained up to $41 \%$ and $17 \%$ of seasonal variations in GPP in croplands and forests, respectively. In a modeling study, Ibrom et al. (2006) found the uniform PAR distribution in the maritime Scottish climate with a ca. $20 \%$ higher $f_{\text {diff }}$ lead to a $13-14 \%$ higher LUE compared to the continental climate in Germany in spruce

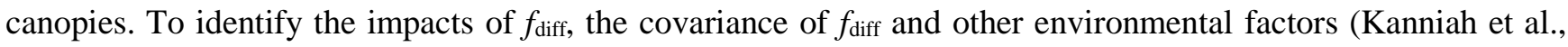
2012) should also be taken into account. For instance, Williams et al. (2016) found that without considering the covariance between $f_{\text {diff }}$ and phenology, the GPP enhancement from $f_{\text {diff }}$ is $260 \%$, while by separating $f_{\text {diff }}$ and phenology, the GPP enhancement induced by $f_{\text {diff }}$ dropped to $22 \%$. Apart from modeling studies at the global scale (Mercado et al., 2009), few studies have focused on ecosystems in high latitude regions, which are radiation and temperature limited (van Dijk et al., 2005; Lagergren et al., 2008). In these ecosystems, the influence of $f_{\text {diff }}$ and its covariance with other environmental variables should be thoroughly quantified, because the potential mechanisms influencing GPP and ET might be different from those of water-limited ecosystems.

Because photosynthesis and transpiration are closely linked via stomatal behaviors, $f_{\text {diff }}$ is expected to also have moderate impacts on land evapotranspiration (ET) and may eventually influence the global hydrological cycle and the climate system (Knohl and Baldocchi, 2008; Davin and Seneviratne, 2012; Pedruzo-Bagazgoitia et al., 2017). For instance, the modeling results from the Community Land Model showed that higher $f_{\text {diff }}$ during 1960 1990 increased the latent heat flux of evapotranspiration ( $\lambda \mathrm{ET}$ ) in the tropics by $2.5 \mathrm{Wm}^{-2}$ ( $3 \%$ of mean) and reduced global river runoff (Oliveira et al., 2011). By employing the COSMO-CLM2 regional climate model, Davin and Seneviratne (2012) identified $f_{\text {diff }}$ could alter the seasonal evaporative fraction (EF, defined as the ratio between $\lambda E T$ and available energy, which is net radiation minus soil heat flux Rn-G) and a consistent fraction (up to $3 \%$ ) of the overall variability in European summer air temperature could be explained by $f_{\text {diff. }}$ With increasing $f_{\text {diff, }}$ the magnitude of the ET increase due to $f_{\text {diff }}$ has been shown to be smaller than that of GPP, resulting in an increase in the ecosystem water use efficiency (WUE, defined as the ratio between GPP and ET) (Knohl and Baldocchi, 2008; Oliveira et al., 2011). Similarly to GPP, the local environment can also alter the responses of ecosystem ET, EF and WUE to $f_{\text {diff. }}$ For instance, in temperature-limited ecosystems at high latitudes, incoming longwave radiation has been shown to be an important source of energy for snow and glacier melting under cloudy conditions with high $f_{\text {diff }}$ increasing surface temperature (Juszak \& Pelliciotti, 2013). However, the impacts of higher longwave radiation on the energy budget and canopy temperature have not been considered yet, despite their potentially important implications for vegetation activities. In general, compared to studies on evaluating impacts of $f_{\text {diff }}$ on GPP and LUE, studies on the influence of $f_{\text {diff }}$ on ET, EF and WUE are limited. More studies are needed to quantify impacts and understand mechanisms linking $f_{\text {diff }}$ to ET, EF and WUE.

Traditionally, models that incorporate satellite remotely sensed observations, e.g. vegetation indices, surface temperature or albedo, to estimate GPP and ET, tend to be biased to clear sky conditions, due to lack of representation of cloudy conditions. These remote sensing models estimating GPP and ET can be classified into 
'top-down' and 'bottom-up' approaches (Houborg et al., 2009). 'Top-down' methods, e.g. CASA (Potter et al., 1993), the MODIS GPP and ET algorithms (Running et al., 2004; Mu et al., 2007) or the Priestley-Taylor Jet Propulsion Laboratory (PT-JPL) ET model (Fisher et al., 2008; Garcia et al., 2013), are simpler and can be directly driven with remote sensing variables. These models try to represent the ecological behavior of the canopy as a whole, using effective variables and few parameters. 'Top-down' models generally estimate GPP and ET assuming that the maximum LUE $\left(\varepsilon_{\max }\right)$ of plant canopies and the maximum ET are constrained by similar stress-constraints reflecting different environmental constraints (Leuning et al., 1995; Houborg and Soegaard, 2004; Houborg et al., 2009; Garcia et al., 2013). 'Top-down' GPP approaches, have the advantage that forcing variables, such as the fraction of absorbed PAR at the top of the canopy or the land surface temperature, can be routinely estimated from remote sensing data instead of using a detailed description of canopy profiles and leaf energy budgets as in 'bottom-up' methods (Wang and Leuning, 1998; Ryu et al., 2011). Due to the impacts on the overall ecosystem GPP and ET, ‘top-down' approaches can also benefit from considering $f_{\text {diff. }}$ For instance, Yuan et al. (2014) found six of the seven LUE GPP models, which did not consider $f_{\text {diff, }}$ significantly underestimated GPP during cloudy days. Recent studies incorporated the sunlit and shaded leaf approach into the MODIS LUE algorithm to improve satellite based GPP estimation (He et al., 2013; Zhou et al., 2015). Donohue et al. (2014) extended Roderick et al.'s (2001) LUE formulation to include the dependency of $\varepsilon_{\max }$ on $f_{\text {diff }}$ and on the light-saturated rate of photosynthesis at the top of the canopy, yielding a highly generic model that accurately predicted GPP across Australia. Wang et al. (2015) added the information of cloudiness index (CI) to improve MODIS LUE algorithm. However, for ‘top-down’ ET models e.g. the Priestley Taylor based PT-JPL ET model, the effects of $f_{\text {diff }}$ have not been investigated previously. Furthermore, it has not been investigated, whether or not the same set of biophysical constraints can be used to down-regulate both GPP and ET.

The outputs of ‘top-down' models can be evaluated against eddy covariance (EC) datasets, including carbon and water fluxes between the land surface and the atmosphere at the ecosystem scale. Long-term eddy covariance and micrometeorological observations are also important to assess the environmental controls of carbon and water exchange (Baldocchi et al., 2003) using statistical approaches, e.g. path analysis (Bassow \& Bazzaz, 1998; Huxman et al., 2003; Wu et al., 2016). In this study, we used a an 11-year time series of EC observations, a joint GPP and ET 'top-down' model and in-situ sap flow observations from a high latitude temperate deciduous forest ecosystem at Soroe in Denmark, to assess the impacts of $f_{\text {diff }}$ on GPP and ET. At this site, $73.54 \%$ of all days are non-clear $\left(f_{\text {diff }}>50 \%\right)$. This percentage is higher than the global average level (ca. 50\%, Kanniah et al., 2012). The specific objectives are: (1) to evaluate how $f_{\text {diff }}$ independently and jointly with other biophysical constraints affects daily carbon and water fluxes in a deciduous forest; (2) to incorporate $f_{\text {diff }}$ as a biophysical constraint into remote sensing based 'top-down' models to improve GPP and ET simulations. This study provides insights on the relative contribution of $f_{\text {diff }}$ to the total variability on daily carbon and water fluxes encountered over multiple years using both statistical path analysis and global sensitivity analysis of 'top-down' models. It also explores potential mechanisms increasing LUE, WUE and evaporative fraction (EF) under diffuse conditions for high latitude ecosystems.

\section{Study site and data}

A Danish temperate deciduous beech forest site (Soroe on Zealand, Denmark, $55^{\circ} 29^{\prime} \mathrm{N}, 11^{\circ} 38^{\prime} \mathrm{E}$ ) has been selected to evaluate the impacts of $f_{\text {diff }}$ on the ecosystem carbon and water fluxes. The Soroe flux site has long- 
term records of eddy covariance fluxes since 1996, diffuse / total PAR measurements during the period from 2004 to 2013, and sap flow data from 2009 to 2011. The mean annual precipitation is $564 \mathrm{~mm}$ and the mean annual temperature is $8.5{ }^{\circ} \mathrm{C}$. The dominant tree species is European beech (Fagus sylvatica L.) with approximately 20\% conifers, mainly Norway spruce (Picea abies (L.) Karst.) and European larch (Larix decidua (Mill.)) (Wu et al., 2013). Leaf area index (LAI) peaks at 4-5 $\mathrm{m}^{2} \cdot \mathrm{m}^{-2}$. Soil was classified as Alfisols or Mollisols with 10-40 cm deep organic layers. Details of this site are reported in Pilegaard et al. (2001) and Pilegaard et al. (2011).

Eddy covariance and micrometeorological observations and satellite data from the Moderate Resolution Imaging Spectroradiometer (MODIS) onboard of TERRA were used. The diffuse and total incoming PAR were measured by the Delta-T BF3 sensor. Eddy covariance and micrometeorological observations include GPP, ET, Rn-G, incoming longwave radiation ( $\left(\mathrm{W}_{\text {in }}\right)$, outgoing longwave radiation $\left(\mathrm{LW}_{\text {out }}\right)$ and incoming shortwave radiation $\left(\mathrm{SW}_{\text {in }}\right.$ ), air temperature (Ta), vapor pressure deficit (VPD) and soil water content (SWC). More details on this dataset can be found in Wu et al. (2012). The initial half-hourly observations were downloaded from the Fluxnet database (https://fluxnet.ornl.gov/), filtered by quality control flags and energy closure errors, and aggregated into daily values. Flag quality controlled GPP and ET observations spanning the period from 2002 to 2012 were used for analysis and modeling. For ET, observations with negative sensible heat flux, latent heat flux and net radiation were further excluded. Sap flow data were measured continuously for six beech trees during the period of 2009-2011 using the stem-heat balance technique (Granier et al., 1985). Averaged data from these six trees were used to represent the ecosystem-scale transpiration and to evaluate the simulated transpiration. Due to technical issues, there were gaps in the sap flow data. The daily ecosystem scale transpiration was only calculated, if more than three tree observations per day are available. Normalized difference vegetation index (NDVI) from the MODIS satellite vegetation index product (MOD13Q1, 16 day composite at 250m resolution L3 product, https://reverb.echo.nasa.gov/) was downloaded to infer the vegetation phenology and to retrieve LAI dynamics from 2002 to 2012. The initial 16-day synthetic data were further smoothed by the Savitzky-Golay filter in order to reduce the impacts of clouds and then interpolated into daily data by the spline algorithm (Chen et al., 2004). Further, LAI was obtained from NDVI by the locally empirical relationship LAI $=0.001306 \mathrm{e}^{9.241 \mathrm{NDVI}}$ from Boegh et al. (2009). Both LAI from MODIS and in-situ measurements by LAI2200C Plant Canopy Analyzer (LI-COR Inc., Lincoln, NE, USA) were shown in Figure 1. In general, LAI from MODIS NDVI captured the seasonal dynamics of vegetation. The peak values are $4-5.5 \mathrm{~m}^{2} \cdot \mathrm{m}^{-2}$ and these match the in-situ measurements and previous studies (Pilegaard et al. 2011; Wu et al., 2013).

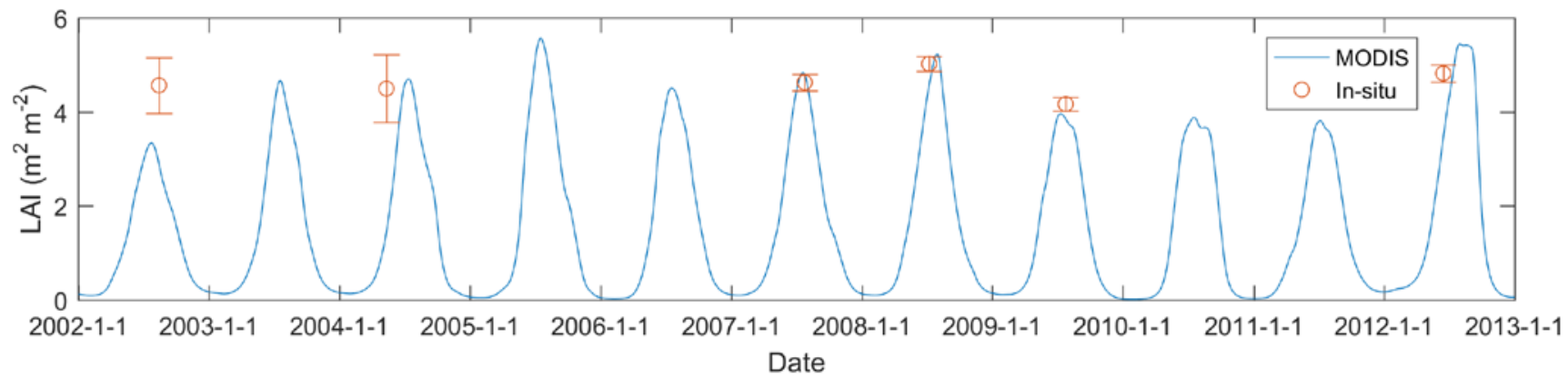

Figure 1. The seasonal variation of LAI derived from MODIS NDVI in Soroe from 2002 to 2012 (continuous line). Dots are in-situ LAI measurements from LAI-2200C and the error bar shows the standard deviation. 
Surface temperature, Ts, was calculated from in-situ incoming and outgoing longwave radiation based on the Stefan-Boltzmann law, as in Eq. (1). The surface emissivity was estimated from NDVI (Van de Griend and Owe, 1993, Eq. 2).

$$
\begin{gathered}
\varepsilon \cdot \sigma \cdot \mathrm{Ts}^{4}=\mathrm{LW}_{\text {out }}-(1-\varepsilon) \cdot \mathrm{LW}_{\text {in }} \\
\varepsilon=\left\{\begin{array}{cc}
0.986 & (\mathrm{NDVI}>0.608) \\
1.0094+0.047 \cdot \ln (\mathrm{NDVI}) & (0.131<\mathrm{NDVI}<0.608) \\
0.914 & (\mathrm{NDVI}<0.131)
\end{array}\right.
\end{gathered}
$$

Where $\mathrm{LW}_{\text {out }}$ is longwave outgoing, $\mathrm{LW}_{\text {in }}$ is longwave incoming. $\varepsilon$ is the surface emissivity and $\sigma$ is the StefanBoltzmann constant $\left(5.670367 \times 10^{-8} \mathrm{~kg} \cdot \mathrm{s}^{-3} \cdot \mathrm{K}^{-4}\right)$. NDVI is from MODIS products. 0.986 is emissivity for dense vegetation (NDVI $>0.608$ ) and 0.914 is emissivity for bare soil (NDVI $<0.131$ ).

$f_{\text {diff }}$ is the ratio between the observed diffuse PAR and the total PAR at the ground (Table 1). It is highly correlated with the atmospheric transmission. Several indices could be used to infer $f_{\text {diff }}$ (Butt et al., 2010). Among them, the cloudiness index (CI), which is one minus the ratio between the observed PAR at ground and PAR at the top of atmosphere (TOA) (Table 1), was often used to represent $f_{\text {diff }}$ (Orgill and Hollands, 1977; Butt et al., 2010; Wang et al., 2015). The advantage of CI is that it only requires one measurement, the total PAR at the surface. The PAR at TOA could be calculated based on the time and the location on the Earth. In order to determine $f_{\text {diff, }}$ ground measurements of both diffuse and total PAR are required. The CI approach was more favorable to be used in places without total and diffuse PAR measurements. In order to make this study more applicable for other regions, CI was adopted as a proxy of $f_{\text {diff }}$ to assess its impacts on carbon and water exchange. Additionally in our data set, $f_{\text {diff }}$ is available from 2004, while CI has a longer time series since 2002. To identify the difference between CI and $f_{\text {diff, }}$ these two indices were compared through statistical correlation and modeling tests.

\section{Methods}

First, statistical analysis was conducted for in-situ eddy covariance and micrometeorological variables from 2002 to 2012 to identify the relationship between CI (a proxy for $f_{\text {diff }}$ ) and observed daily GPP, ET, LUE, EF and WUE. Then, a joint GPP and ET ‘top-down’ parsimonious model was used to simulate daily GPP and ET. The model is based on the remote sensing LUE GPP model (Potter et al., 1993; Monteith et al., 1972) and PriestleyTaylor Jet Propulsion Laboratory ET model (PT-JPL, Fisher et al., 2008). In this model, the same biophysical constraints were used to reduce GPP and ET from potential to actual values. Model accuracy was compared for the cases with and without considering CI. A global sensitivity analysis (GSA, Saltelli et al., 2010) was used to quantify the sensitivity of GPP and ET to $f_{\text {diff. }}$ Both statistical analysis and model based GSA provide estimates of the independent and joint effects of CI on environmental variables. Their results were compared in order to thoroughly understand effects of CI and related meteorological variables on the carbon and water exchange.

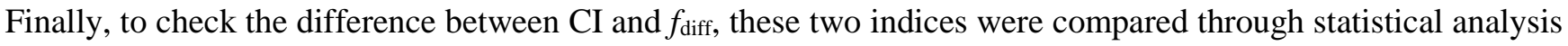
and modeling tests. 


\subsection{Statistical analysis}

To qualitatively explore the responses of GPP and ET to different levels of CI, relationships for GPP vs. PAR, ET vs. Rn-G, ET vs. PAR were analyzed under predominantly diffuse $(\mathrm{CI}>0.66)$ or direct $(\mathrm{CI}<0.33)$ radiation conditions. We chose 0.66 and 0.33 as thresholds to have equal intervals between 0 and 1 , following the thresholds adopted in Davin and Seneviratne (2012). It has been shown in other ecosystems that CI can covariate with vegetation phenology obscuring the actual contribution of CI to GPP (Williams et al., 2016). To address that and control for the phenology effect on GPP and ET, we compared LUE, EF and WUE under diffuse or direct radiation conditions for different levels of NDVI, to make sure that they reflect the same phonological state. Afterwards, path analysis was used to quantitatively assess these relationships. These results informed parsimonious model design by identifying the most important drivers of GPP and ET in this ecosystem. The statistical tests were performed in a significance level of $\mathrm{p}<0.05(1.96 \times$ Standard Error).

Path analysis is a multiple regression technique that considers the covariance among variables. It is mainly used for variables that are highly correlated ( $\mathrm{Li}, 1975)$ e.g. PAR, Ta and VPD. This method has been applied to evaluate environmental controls on carbon exchange in various ecosystems (Bassow \& Bazzaz, 1998; Huxman et al., 2003; Wu et al., 2016). It assumes that the correlation between variable i and dependent variable y can be decomposed into direct and indirect effects. Where the direct effect means that input variable i directly affects output variable $y$. The direct value is also called path value and is the standardized partial regression coefficient. The indirect effects consider how variable i influences another variable $\mathrm{j}(\mathrm{j} \neq \mathrm{i}$ ) which in turn affects the output $\mathrm{y}$. For example, a direct effect of CI on GPP will reflect the net change in GPP due to solely CI, while the rest of variables (e.g. PAR or air temperature) are fixed. However, the indirect effect will reflect how CI influences other environmental variables (e.g. PAR or air temperature) and in turn, these variables influence GPP. These direct and indirect effects represent the relative strength of a given relationship. Eq. 3 shows the formulas for this decomposition.

$$
r_{i, y}=r_{i, 1} P_{1, y}+r_{i, 2} P_{2, y}+\cdots+r_{i, i} P_{i, y}+\cdots+r_{i, n} P_{n, y} \quad(\mathrm{i}=1,2,3, \ldots, \mathrm{n})(\text { Eq. 3) }
$$

Where $r_{i, y}$ is the correlation coefficient between input variable i and ouput $\mathrm{y}$. It decomposes into the direct effect $P_{i, y}$ and indirect effects $r_{i, n} P_{n, y}(\mathrm{n} \neq \mathrm{i}) . P_{i, y}$ is the direct effect from input variable i to output variable y. $r_{i, n}$ is the correlation coefficient between the variable $\mathrm{i}$ and variable n. $r_{i, n} * P_{n, y}(\mathrm{n} \neq \mathrm{i})$ are the indirect effects. The indirect effect quantifies the effect of one variable on another variable, which in turn affects the dependent variable.

To provide a quantitative assessment of the contribution of diffuse/direct PAR to the daily variability of carbon and water fluxes over 11 years and its interactions with other environmental variables, path analysis was performed considering the effect of various environmental factors on the target variables at the daily time scale from 2002 to 2012. Besides CI, environmental factors include Ta, PAR, Rn-G, LAI, VPD and SWC. Target variables are GPP, $\lambda E T$, LUE, EF and WUE. 
To simulate the effects of $f_{\text {diff }}$ on GPP and ET, a joint LUE GPP and PT-JPL ET model was used. Both approaches estimate GPP or ET under potential conditions and then the potential values are down-regulated by the same biophysical constraints reflecting multiple limitations or stresses. These constraints can be derived from remote sensing and atmospheric data (McCallum et al., 2009; Garcia et al, 2013). The LUE GPP model is recognized as a robust method to estimate GPP across various ecosystems and climate regimes (McCallum et al., 2009). The PT-JPL ET model has been demonstrated as one of best-performing global remote sensing ET algorithms in multi-algorithm inter-comparisons (Chen et al., 2014; Ershadi et al., 2014; Vinukollu, Meynadier et al., 2011; Vinukollu, Wood et al., 2011; Michel et al., 2016; Miralles et al., 2016). Therefore, these two 'topdown' GPP and ET models were selected for this study.

Most widely used LUE models e.g. CASA (Potter et al., 1993) or the MODIS algorithm (Running et al., 2004) are based on the assumption that plants optimize canopy LUE or whole canopy carbon gain per total PAR absorbed (Monteith et al., 1972). They have common features to estimate GPP: (1) ecosystem GPP is directly related to absorbed PAR (APAR) through LUE, and (2) LUE may be reduced below its theoretical potential value by environmental stresses such as low temperature or water shortage (Landsberg, 1986). The general form of the LUE GPP model used in this study is shown in Eq. (4) and it is partly based on the Carnegie-AmesStanford-Approach (Potter et al., 1993) with improvements by including constraints to account for fraction of the canopy that is photosynthetically active vegetation (Fisher et al., 2008).

$$
\mathrm{GPP}=\varepsilon_{\max } \cdot \operatorname{PARc} \cdot f_{g} \cdot f_{M} \cdot f_{T a} \cdot f_{V P D} \cdot f_{S W C}
$$

Where GPP is the gross primary productivity $\left(\mathrm{g} \cdot \mathrm{C} \cdot \mathrm{m}^{-2} \cdot \mathrm{d}^{-1}\right) \cdot \varepsilon_{\max }$ is the maximum LUE $\left(\mathrm{g} \cdot \mathrm{C} \cdot \mathrm{MJ}^{-1}\right)$. PARc is the daily photosynthetically active radiation (PAR) $\left(\mathrm{MJ} \cdot \mathrm{m}^{-2} \cdot \mathrm{d}^{-1}\right)$ intercepted by the canopy and it is calculated based on the extinction of PAR within the canopy using the Beer Lambert law (Table 1). $f_{g}$ is the green canopy fraction indicating the proportion of active canopy. $f_{M}$ is the plant moisture constraint. $f_{T a}$ is the air temperature constraint reflecting the temperature limitation of photosynthesis. $f_{V P D}$ is the VPD constraint reflecting the stomatal response to the atmospheric water saturation deficit. $f_{S W C}$ is the soil moisture constraint on photosynthesis. All these constraints range from 0 and 1 and represent the reduction of maximum GPP under limiting environmental conditions. For more details, see Table 1 and Fisher et al., (2008).

The Priestley-Taylor Jet Propulsion Laboratory model (PT-JPL, Fisher et al., 2008) is based on the Priestley and Taylor (1972) equation for potential evapotranspiration, and incorporates eco-physiological variables to downregulate potential evapotranspiration to actual evapotranspiration. PT-JPL is a three source evapotranspiration model, which includes wet surface evaporation (Ei), transpiration (Ec) and soil evaporation (Es), as descripted in equations (5-8).

$$
\lambda \mathrm{ET}=\lambda \mathrm{Ei}+\lambda \mathrm{Ec}+\lambda \mathrm{Es}
$$

$$
\lambda \mathrm{Ei}=f_{w e t} \cdot \alpha \Delta /(\Delta+\gamma) \cdot \mathrm{Rnc}
$$

$$
\lambda \mathrm{Ec}=\left(1-f_{w e t}\right) \cdot f_{g} \cdot f_{M} \cdot f_{T a} \cdot \alpha_{c} \Delta /(\Delta+\gamma) \cdot \mathrm{Rnc}
$$

$$
\lambda \mathrm{Es}=f_{S W C} \cdot \alpha \Delta /(\Delta+\gamma) \cdot(\mathrm{Rns}-\mathrm{G})
$$


Where $\lambda \mathrm{ET}$ is the latent heat flux for total evapotranspiration $\left(\mathrm{W} \cdot \mathrm{m}^{-2}\right), \lambda \mathrm{Ei}$ is evaporation of intercepted water $\left(\mathrm{W} \cdot \mathrm{m}^{-2}\right), \lambda \mathrm{Ec}$ is transpiration $\left(\mathrm{W} \cdot \mathrm{m}^{-2}\right)$, and $\lambda \mathrm{Es}$ is evaporation of soil water $\left(\mathrm{W} \cdot \mathrm{m}^{-2}\right)$. The quantity $f_{\text {wet }}$ is the relative surface wetness to partition the evapotranspiration from the intercepted water and canopy transpiration (Fisher et al., 2008). The symbols $f_{g}, f_{M}, f_{T a}$ and $f_{S W C}$ denote biophysical constraints and have the same meaning as in Eq. 4. $f_{\text {wet }}$ They vary from 0 to 1 to account for the relative reduction of potential $\lambda \mathrm{ET}$ under limiting environmental conditions. Rnc and Rns are the net radiation for canopy and soil, respectively. The partitioning of PAR and net radiation between canopy and soil is calculated following the Beer-Lambert law (Table 1). G is the ground heat flux. $\Delta$ is the slope of saturation-to-vapor pressure curve. $\gamma$ is the psychrometric constant. $\alpha$ is an empirical ratio of potential evapotranspiration to equilibrium potential evapotranspiration (PT coefficient) replacing the atmospheric demand and surface resistance effects in the Penman-Monteith ET equation. Here for $\lambda \mathrm{Ei}$ and $\lambda \mathrm{Es}, \alpha$ is equal to 1.26. This is also the suggested value for the PT-JPL model (Fisher et al., 2008). $\alpha_{c}$ is the coefficient for $\lambda \mathrm{Ec}$ and it is the only parameter in the model that requires calibration.

In order to make the models parsimonious and robust, only those constraints/variables having significant relationships with GPP and $\lambda$ ET were included in the LUE and PT-JPL models. Table 1 shows the detailed information on the model constraints and parameters for LUE and PT-JPL models.

Table 1. Model parameters and equations. SZA is the sun zenith angle. The extinction coefficients for PAR ( $\left.k_{\text {PAR }}\right)$ and for net radiation $\left(\mathrm{k}_{\mathrm{Rn}}\right)$ were equal to 0.5 and 0.6, respectively (Ross, 1976; Impens \& Lemur, 1969; Fisher et al., 2008), RH is the relative humidity.

\begin{tabular}{|c|c|c|c|}
\hline Parameter & Description & Equation & Reference \\
\hline$f_{g}$ & Green canopy fraction & $f_{g}=f_{A P A R} / f_{I P A R}$ & $\begin{array}{l}\text { Fisher et al., } \\
2008\end{array}$ \\
\hline$f_{M}$ & Plant moisture constraint & $f_{M}=f_{A P A R} / \max \left(f_{A P A R}\right)$ & $\begin{array}{l}\text { Fisher et al., } \\
\quad 2008\end{array}$ \\
\hline$f_{T a}$ & Plant temperature constraint & $\begin{array}{c}f_{T a}=1.1814 \cdot\left[1+\mathrm{e}^{0.3\left(-\mathrm{T}_{\mathrm{o}}-10+\mathrm{Ta}\right)}\right]^{-1}[1 \\
\left.+\mathrm{e}^{0.2\left(\mathrm{~T}_{\mathrm{o}}-10-\mathrm{Ta}\right)}\right]^{-1}\end{array}$ & $\begin{array}{l}\text { Potter et al., } \\
1993\end{array}$ \\
\hline$f_{S W C}$ & Soil moisture constraint & $f_{S W C}=\frac{S W C-S W C_{\min }}{S W C_{\max }-S W C_{\min }}$ & $\begin{array}{l}\text { Fisher et al., } \\
2008\end{array}$ \\
\hline$f_{V P D}$ & Vapor pressure deficit constraint & $f_{V P D}=1 /(1+\mathrm{VPD} / \mathrm{D} 0)$ & $\begin{array}{c}\text { Lohammar et al., } \\
1980\end{array}$ \\
\hline$f_{\text {wet }}$ & Relative surface wetness & $f_{w e t}=\mathrm{RH}^{4}$ & $\begin{array}{l}\text { Fisher et al., } \\
2008\end{array}$ \\
\hline$f_{c i}$ & Cloudiness index constraint & $f_{c i}=1-\frac{\mathrm{CI}-\mathrm{CI}_{\min }}{\mathrm{CI}_{\max }-\mathrm{CI}_{\min }}$ & This study \\
\hline$f_{d i}$ & Fraction of diffuse PAR constraint & $f_{\text {di }}=\frac{f_{\text {diff }}-\min \left(f_{\text {diff } f}\right)}{\max \left(f_{\text {diff }}\right)-\min \left(f_{\text {diff }}\right)}$ & This study \\
\hline PARc & PAR intercepted by the canopy & $\mathrm{PARc}=\mathrm{PAR}-\mathrm{PARs}$ & $\begin{array}{l}\text { Ruimy et al., } \\
1999\end{array}$ \\
\hline PARs & PAR for the soil & PARs $=\mathrm{PAR} \cdot \mathrm{e}^{\frac{-\mathrm{k}_{\mathrm{PAR}} \cdot \mathrm{LAI}}{\cos (\mathrm{SZA})}}$ & $\begin{array}{l}\text { Ruimy et al., } \\
1999\end{array}$ \\
\hline Rnc & Net radiation for the canopy & $\mathrm{Rnc}=\mathrm{Rn}-\mathrm{Rns}$ & $\begin{array}{l}\text { Fisher et al., } \\
\quad 2008\end{array}$ \\
\hline Rns & Net radiation for the soil & $\mathrm{Rns}=\mathrm{Rn} \cdot \mathrm{e}^{\frac{-\mathrm{k}_{\mathrm{Rn}} \cdot \mathrm{LAI}}{\cos (S Z A)}}$ & $\begin{array}{l}\text { Fisher et al., } \\
2008\end{array}$ \\
\hline
\end{tabular}




\begin{tabular}{|c|c|c|c|}
\hline LAI & Leaf area index & $\mathrm{LAI}=0.001306 \mathrm{e}^{9.241 \mathrm{NDVI}}$ & $\begin{array}{l}\text { Boegh et al., } \\
2009\end{array}$ \\
\hline$f_{A P A R}$ & $\begin{array}{l}\text { Fraction of PAR absorbed by green } \\
\text { vegetation cover (SAVI: soil adjusted } \\
\text { vegetation index) }\end{array}$ & $\begin{array}{c}\mathrm{SAVI}=0.45 \mathrm{NDVI}+0.132 \\
f_{\mathrm{APAR}}=1.4 \mathrm{SAVI}-0.05\end{array}$ & $\begin{array}{l}\text { Fisher et al., } \\
\quad 2008\end{array}$ \\
\hline$f_{I P A R}$ & $\begin{array}{c}\text { Fraction of PAR intercepted by total } \\
\text { vegetation cover }\end{array}$ & $f_{\mathrm{IPAR}}=1.0 \mathrm{NDVI}-0.05$ & $\begin{array}{l}\text { Fisher et al., } \\
2008\end{array}$ \\
\hline CI & Cloudiness index & $\mathrm{CI}=1-\mathrm{PAR}_{\mathrm{obs}} / \mathrm{PAR}_{\mathrm{TOA}}$ & $\begin{array}{l}\text { Spitters et al., } \\
1986\end{array}$ \\
\hline$f_{\text {diff }}$ & Fraction of diffuse PAR & $f_{\text {diff }}=\mathrm{PAR}_{\text {diffuse }} / \mathrm{PAR}_{\text {total }}$ & $\begin{array}{l}\text { Spitters et al., } \\
1986\end{array}$ \\
\hline To & Optimum plant growth temperature & $\begin{array}{c}\text { Ta at } \max \left\{\mathrm{PAR} \cdot f_{A P A R} \cdot \mathrm{Ta} / \mathrm{VPD}\right\} \\
16.51{ }^{\circ} \mathrm{C} \text { for this study }\end{array}$ & $\begin{array}{l}\text { Fisher et al., } \\
2008\end{array}$ \\
\hline D0 & Empirical coefficient for VPD & $15 \mathrm{hPa}$ & $\begin{array}{c}\text { Leuning et al., } \\
1995\end{array}$ \\
\hline
\end{tabular}

341

$342 \quad 3.3$ Incorporating diffuse fraction into the joint GPP and ET model

Previous studies have improved the LUE GPP models by considering the impacts of CI on LUE (e.g. Turner et al., 2006; Wang et al., 2015; Wu et al., 2016). For this study, we used a similar approach to modify Eq. (4) to incorporate the CI constraint into the GPP model, as Eq. (9). Moreover, $\varepsilon_{\max }$ now represents the maximum LUE under totally diffuse radiation conditions instead of the maximum value for all sky conditions.

347

In the PT-JPL model, the PT coefficient $(\alpha)$ represents the atmospheric demand and the surface resistance for ET.

348 Therefore, similar to the maximum LUE $\varepsilon_{\max }$ in the GPP model, this study incorporated CI into ET via changes 349 in the PT coefficient $\left(\alpha_{c}\right)$, which reflects the opening of stomata and stomatal conductance.

$$
G P P=\left(1-\mu \cdot f_{c i}\right) \cdot \varepsilon_{\max } \cdot \operatorname{PARc} \cdot f_{g} \cdot f_{M} \cdot f_{T a} \cdot f_{V P D} \cdot f_{S W C}
$$

$$
\lambda \mathrm{Ec}=\left(1-\tau \cdot f_{c i}\right) \cdot\left(1-f_{w e t}\right) \cdot f_{g} \cdot f_{T a} \cdot f_{M} \cdot \alpha_{c} \Delta /(\Delta+\gamma) \cdot \operatorname{Rnc}
$$

Where $f_{g}, f_{M}, f_{T a}, f_{V P D}, f_{S W C}, f_{w e t}$ have the same meaning as Eq. (2) and (7). PARc and Rnc are the PAR and

$\mathrm{Rn}$ intercepted by the canopy, respectively. $\left(1-\mu \cdot f_{c i}\right)$ and $\left(1-\tau \cdot f_{c i}\right)$ are the subtractive formulas to represent the fraction of diffuse PAR constraints for GPP and ET, respectively. $\mu$ indicates an overall sensitivity of GPP to CI. $\tau$ reflects the sensitivity of $\lambda \mathrm{Ec}$ to CI. In these approaches, $f_{\mathrm{ci}}$ can also be replaced by $f_{d i}$, in order to drive the model with $f_{\text {diff }}$ instead.

\subsection{Model calibration and validation}

The LUE GPP model version without considering diffuse light (Eq. 2) had only one parameter, $\varepsilon_{\max }$ (maximum LUE) to be optimized or adjusted to the vegetation type. In the new diffuse/direct model version (Eq. 9), an additional parameter $\mu$ (the sensitivity of GPP to CI) needs to be optimized as well. In the initial PT-JPL ET model (Eq. 7), the $\alpha_{c}$ parameter was optimized, while in the modified PT-JPL ET model (Eq. 10), $\tau$ (the 
sensitivity of $\lambda \mathrm{Ec}$ to $\mathrm{CI}$ ) needs to be optimized additionally. Table 2 shows the details on these calibrated parameters.

Table 2. The calibrated parameters for the joint GPP and ET model

\begin{tabular}{|c|c|c|c|c|c|}
\hline Models & Parameter & Without CI (Eq. 4 and 7) & With CI (Eq. 9 and 10) & Range & $\begin{array}{c}\text { Optimized value } \\
\text { (Without CI / with CI) }\end{array}$ \\
\hline \multirow[t]{2}{*}{ GPP } & $\varepsilon_{\max }$ & $\begin{array}{l}\underset{2}{\operatorname{Maximum} \mathrm{LUE}}\left(\mathrm{g} \cdot \mathrm{C} \cdot \mathrm{m}^{-1}\right. \\
\end{array}$ & $\begin{array}{l}\text { Maximum LUE under total diffuse PAR } \\
\text { conditions }\left(\mathrm{g} \cdot \mathrm{C} \cdot \mathrm{m}^{-2} \cdot \mathrm{MJ}^{-1}\right)\end{array}$ & $0 \sim 5$ & $2.97 / 4.29$ \\
\hline & $\mu$ & & GPP sensitivity to $f_{C I}$ (dimensionless) & $-1 \sim 1$ & 0.46 \\
\hline \multirow[t]{2}{*}{ ET } & $\alpha_{c}$ & $\begin{array}{l}\text { PT coefficient for the } \\
\text { canopy (dimensionless) }\end{array}$ & $\begin{array}{l}\text { PT coefficient for the canopy under total } \\
\text { diffuse PAR conditions (dimensionless) }\end{array}$ & $1 \sim 3$ & $1.32 / 2.60$ \\
\hline & $\tau$ & & $\lambda$ Ec sensitivity to $f_{C I}$ (dimensionless) & $-1 \sim 1$ & 0.65 \\
\hline
\end{tabular}

366

367

368

369

370

371

372

373

374

375

376

377

378

379

380

381

382

383
The Monte Carlo method was used to optimize these model parameters, with RMSE (root mean square error) as the objective function. The parameter values were sampled 20,000 times with uniform distribution within their corresponding ranges and these 20,000 parameter sets were used to run models. Odd years were used for calibration and even years were for validation. The best-fit parameter set was chosen.

To compare model simulation performances with and without CI information, the Root Mean Square Error (RMSE, Eq. 11), Correlation Coefficient (R, Eq. 12), Bias (Eq. 13), unbiased Root Mean Square Error (ubRMSE, Eq. 14) and Standard Deviation (STD, Eq. 15) were used. Taylor diagrams (Taylor, 2001), were used to present these three complementary statistics CC, Normalized STD (NSTD, as Eq. 16) and Normalized ubRMSE (NubRMSE), which have a triangle-cosine-law-like relationship, as Eq. (17). The radial distance stands for the NSTD and the angle in the polar plot represents $R$. The reference point located on the X-axis with $R=1, N S T D=1$ and NubRMSE $=0$ is the observation. The distance from the simulation point to the reference point means the NubRMSE of simulations and it is the integrated performance for the simulation.

$$
\begin{gathered}
\text { RMSE }=\sqrt{\sum_{\mathrm{i}=1}^{\mathrm{N}}\left(\operatorname{sim}_{\mathrm{i}}-\mathrm{obs}_{\mathrm{i}}\right)^{2} / \mathrm{N}} \\
\mathrm{R}=\frac{\sum_{\mathrm{i}=1}^{\mathrm{N}}\left(\operatorname{sim}_{\mathrm{i}}-\overline{\operatorname{sim}}\right)\left(\mathrm{obs}_{\mathrm{i}}-\overline{\mathrm{obs}}\right)}{\sqrt{\sum_{\mathrm{i}=1}^{\mathrm{N}}\left(\operatorname{sim}_{\mathrm{i}}-\overline{\mathrm{sIm}}\right)^{2}} \times \sqrt{\sum_{\mathrm{i}=1}^{\mathrm{N}}\left(\mathrm{obs}_{\mathrm{i}}-\overline{\mathrm{obs}}\right)^{2}}}
\end{gathered}
$$

$$
\text { ubRMSE }=\sqrt{\sum_{\mathrm{i}=1}^{\mathrm{N}}\left[\left(\operatorname{sim}_{\mathrm{i}}-\overline{\operatorname{slm}}\right)-\left(\mathrm{obs}_{\mathrm{i}}-\overline{\mathrm{obs}}\right)\right]^{2} / \mathrm{N}}
$$

$$
\mathrm{STD}=\sqrt{\sum_{\mathrm{i}=1}^{\mathrm{N}}(\operatorname{sim}-\overline{\operatorname{sim}})^{2} / \mathrm{N}}
$$

$$
\mathrm{NSTD}_{\text {sim }}=\mathrm{STD}_{\text {sim }} / \mathrm{STD}_{\mathrm{obs}}
$$


Where sim is the simulation, obs is the observation, $\mathrm{N}$ is the total number, $\overline{\mathrm{sim}}$ is the average of the simulation, and $\overline{\mathrm{obs}}$ is the average of the observation.

\subsection{Global sensitivity analysis}

The Sobol' method (Sobol' et al., 1990) is one of the most commonly used global sensitivity analysis (GSA) methods. It is based on ANOVA (analysis of variance) decomposition and it allows calculating the sensitivity of coupled input forcing. The Sobol' method provides not only the first order sensitivity for each forcing factor but can also quantify interactions among forcing factors. The first order sensitivity quantifies the independent contribution from each forcing to the output variable, while the second order quantifies the interactions between each two forcing factors to the output variable. In our study, we aimed to identify the sensitivity of GPP and $\lambda$ ET to $f_{\mathrm{ci}}$, in relation with other major environmental variables and assess if the model approach could pick the same sensitivities embedded in the dataset that will be captured by the path analysis. The variances of the terms in the ANOVA decomposition are estimated the following equations (Saltelli et al., 2010):

$$
\mathrm{V}(\mathrm{Y})=\sum_{\mathrm{i}=1}^{\mathrm{n}} \mathrm{V}_{\mathrm{i}}+\sum_{\mathrm{i} \leq \mathrm{j}}^{\mathrm{n}} \mathrm{V}_{\mathrm{ij}}+\cdots+\sum_{1 \leq \cdots \leq n}^{\mathrm{n}} \mathrm{V}_{1 \ldots \mathrm{n}}
$$

Where $V_{i}$ represents the first order effect for each factor $X_{i}$; $V_{i j}$ stands for the second order effect for $X_{i}, X_{j}$; and $V_{1 \ldots n}$ is the $n^{\text {th }}$ order effect for $\mathrm{X}_{1}, \ldots, \mathrm{X}_{\mathrm{n}}$.

The first order sensitivity index $S_{i}$ can be calculated by

$$
\mathrm{S}_{\mathrm{i}}=\mathrm{V}_{\mathrm{i}} / \mathrm{V}(\mathrm{Y})=\mathrm{V}\left[\mathrm{E}\left(\mathrm{Y} \mid \mathrm{X}_{\mathrm{i}}\right)\right] /(\mathrm{V}(\mathrm{Y}))
$$

And the second-order sensitivity index $S_{i j}$ can be calculated by

$$
S_{i j}=V_{i j} / V(Y)=\left(V\left[E\left(Y \mid X_{i}, X_{j}\right)\right]-V_{i}-V_{j}\right) /(V(Y))
$$

In general, the total sensitivity index can be defined as:

$$
\mathrm{S}_{\mathrm{i}}^{\text {tot }}=\mathrm{E}\left(\mathrm{V}\left(\mathrm{Y} \mid \mathrm{X}_{\sim \mathrm{i}}\right)\right) / \mathrm{V}(\mathrm{Y})
$$

Where S stands for different order sensitivity index, $\mathrm{V}$ means the variance for different variables, $\mathrm{E}$ is the expectation, and $\sim$ i refers to all of the inputs except input $i$.

The kernel density sampling method was applied to sample the input data set for sensitivity analysis. The advantage to use the kernel density sampling method is that it could resemble the distribution of sampled data set. According to the kernel density distribution of each model input, 20,000 samples will be generated to assess the model input sensitivity.

4. Results and discussion

4.1 Statistical analysis 
417 First, we explored responses of daily GPP and $\lambda$ ET to diffuse/direct radiation conditions while controlling for 418 radiation levels. Daily GPP and $\lambda \mathrm{ET}$ from the eddy covariance flux tower were compared between 419 predominately diffuse PAR conditions $(\mathrm{CI}>0.66)$ and predominately direct PAR conditions $(\mathrm{CI}<0.33)$ over the 420 period from 2002 to 2012. Direct comparison for diffuse and direct radiation conditions could involve data from 421 different days of the year with different phenology conditions and this comparison could exaggerate the actual

422

423

424

425

426

427

428

429

430

431

432

433

434

435

436

437

438

439

440

441

442

443

444

445

446

447

448 diffuse fertilization effects (Williams et al., 2016). In order to compare the responses of daily GPP and $\lambda$ ET with the phenology background, comparison in Figure 2 (a-c) was conducted with NDVI more than 0.75. Figure 2 (ac) shows the evolution of GPP and $\lambda E T$ as a function of PAR and Rn-G with predominantly diffuse and direct PAR conditions, respectively. There is a clear distinction of the response of GPP to PAR between diffuse and direct PAR conditions. As shown in Figure 2 (a), with PAR increasing, GPP increased significantly in the diffuse PAR conditions, while GPP increased slowly in the direct PAR conditions. The slope of the response curve represents LUE. This suggests that LUE in the diffuse PAR is higher than that in the direct radiation. The evolution of $\lambda E T$ as a function of PAR or Rn-G in diffuse and direct radiation conditions is shown in the Figure 2 (b) and (c), respectively. Similar to the response of GPP, $\lambda E T$ is higher under predominately diffuse PAR conditions for the same level of PAR or Rn-G. However, the increase in $\lambda \mathrm{ET}$ is less obvious than that in GPP and this leads to the increase of WUE. These results are in agreement with a study on a deciduous temperate forest ecosystem of central Germany, which found that the diffuse/direct radiation could increase the ecosystem WUE (Knohl and Baldocchi, 2008). The slope of the response curve in Figure 2 (c) represents the evaporative fraction (EF), the ratio of between $\lambda E T$ and Rn-G. This suggests that under diffuse PAR, higher photosynthesis rates lead to higher $\lambda \mathrm{ET}$ and higher EF. It should be also noticed that the difference for response curves in $\lambda \mathrm{ET}$ vs. PAR is clearer than that in $\lambda E T$ vs. Rn-G. PAR does not include the information on the longwave radiation, while Rn-G contains the longwave radiation components. That indicates that longwave radiation components induced the difference between $\lambda E T$ vs. PAR and $\lambda E T$ vs. Rn-G.

To further explore the responses of daily LUE, EF and WUF to diffuse/direct radiation conditions, LUE, EF and WUE were compared with various levels of NDVI under predominately diffuse and direct PAR conditions, as shown in Figure 2 (d-f). In general, there is a significant difference for the response curves of diffuse and direct PAR conditions in LUE, EF and WUE. This indicates the ecosystem responds differently to the diffuse and direct PAR conditions. With higher levels of NDVI, the difference of LUE, EF and WUE between predominately diffuse conditions and predominately direct radiation conditions becomes more significant. This indicates diffuse PAR has stronger effects in high NDVI conditions. This is in agreement with the findings that in the ecosystem with high LAI, the diffuse fertilization effects are stronger (Alton et al., 2007). 

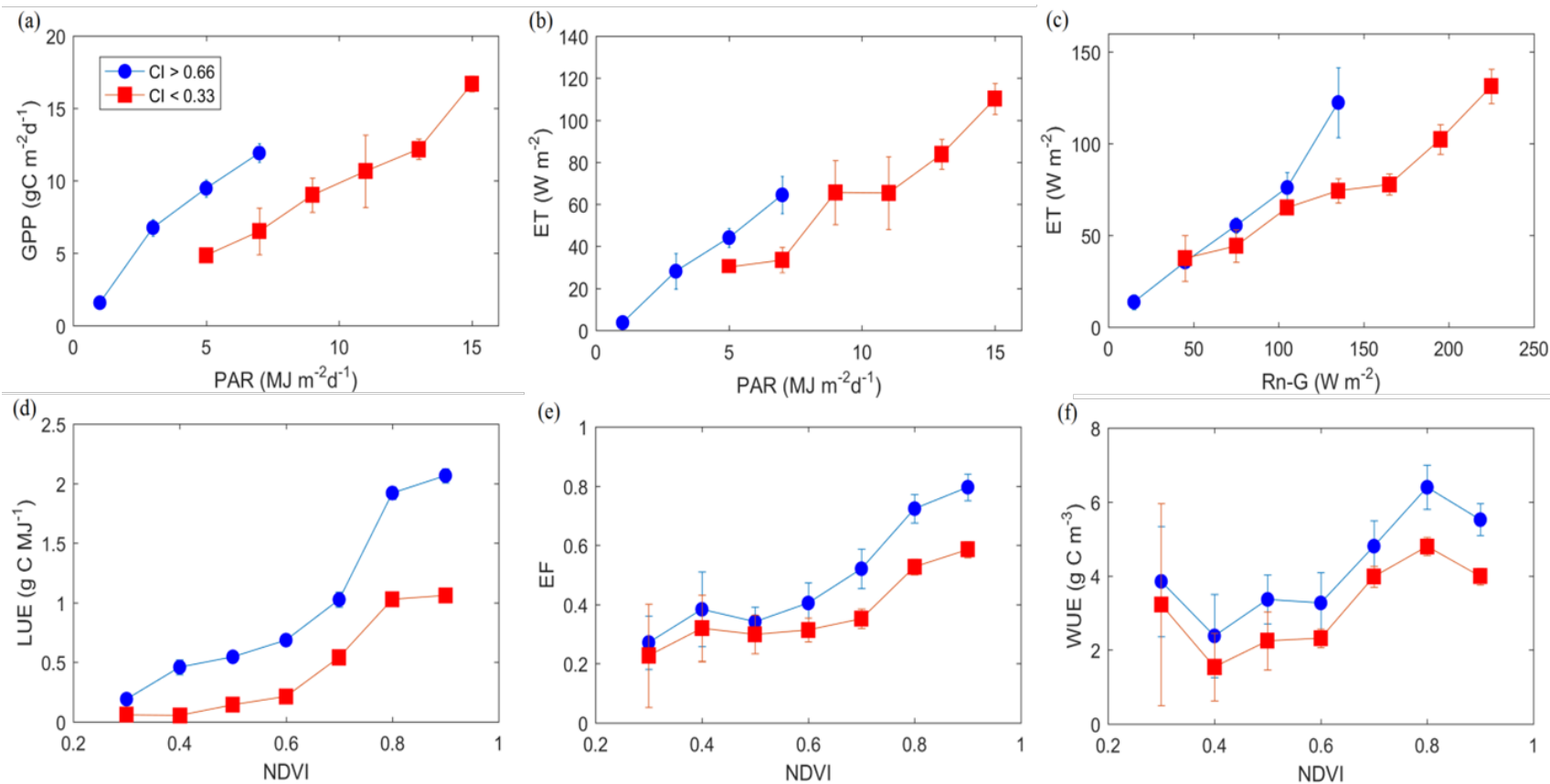

450

451

452

453

454

455

456

457

458

459

460

461

462

463

464

465

466

467

468

469

470

471

472

Figure 2. The response of daily GPP, $\lambda E T$, LUE, EF and WUE to diffuse and direct radiation conditions during the period from 2002 to 2012. The thresholds for predominantly diffuse and direct conditions are defined as CI above 0.66 and below 0.33, respectively. (a) GPP as a function of PAR for predominantly diffuse light condition (CI $>0.66)$ and predominantly direct light conditions $(\mathrm{CI}<0.33)$. (b) $\lambda \mathrm{ET}$ as a function of PAR for predominantly diffuse and direct light conditions. (c) $\lambda \mathrm{ET}$ as a function of Rn-G for predominantly diffuse and direct conditions. (d) LUE as a function of NDVI for predominantly diffuse and direct conditions. (e) EF as a function of NDVI for predominantly diffuse and direct conditions. (f) WUE as a function of NDVI for predominantly diffuse and direct conditions. The points represent the mean value for specific PAR interval and the error bar represent the significance level at $\mathrm{p}<0.05$ (1.96×Standard Error). To exclude the influence from phenology, comparison in (a-c) were conducted with NDVI more than 0.75 .

The results of the path analysis are shown in Table 3-5. Table 3 presents the total effects (correlation coefficients) among these important variables. CI has positive correlation with LUE, EF, EF* and WUE, while it negatively correlates with GPP, $\lambda \mathrm{ET}$ and $\lambda \mathrm{ET}^{*} . \lambda \mathrm{ET}^{*}$ and $\mathrm{EF}^{*}$ are the observations with LAI greater than 2 and VPD larger than $3.5 \mathrm{hPa}$. LAI greater than 2 corresponds to the growing season, while VPD larger than $3.5 \mathrm{hPa}$ is associated with lack of precipitation and limited evaporation of intercepted water. Both Ta and LAI positively correlate with GPP, LUE, $\lambda E T, \lambda E T^{*}, \mathrm{EF}, \mathrm{EF}^{*}$ and WUE. PAR also has positive correlation with GPP, LUE and WUE. Rn-G has positive correlations with $\lambda \mathrm{ET}, \lambda \mathrm{ET}^{*}$ and EF. This indicates that the ecosystem dynamics are controlled by temperature and radiation. During the growing season,there is a negative correlation between VPD and $\mathrm{EF}^{*}$, reflecting stomatal control of transpiration. This can be seen also in the negative correlation of VPD with $\mathrm{EF}^{*}$. Even though there are parts of the year when the ecosystem is water controlled, the overall dynamics are controlled by energy and temperature. This is supported by the negative correlation of SWC with GPP, LUE, $\lambda \mathrm{ET}$ and EF. The relation is only positive during high VPD and growing season periods ( $\left.\lambda \mathrm{ET}^{*}\right)$. In water-limited 
Table 3. The total effects (correlation coefficients) from environmental factors to target variables

\begin{tabular}{cccccccc}
\hline Total effects & CI & Ta & PAR & Rn-G & LAI & VPD & SWC \\
\hline GPP & -0.47 & 0.78 & 0.84 & $/$ & 0.84 & 0.72 & -0.31 \\
LUE & 0.11 & 0.71 & 0.28 & $/$ & 0.73 & 0.27 & -0.36 \\
$\lambda$ ET & -0.29 & 0.73 & $/$ & 0.76 & 0.77 & 0.64 & -0.26 \\
$\lambda$ ET $^{*}$ & -0.21 & 0.15 & $/$ & 0.68 & 0.34 & 0.29 & 0.25 \\
EF & 0.12 & 0.59 & $/$ & 0.11 & 0.63 & 0.21 & -0.31 \\
EF* & 0.44 & 0.12 & $/$ & -0.36 & 0.20 & -0.19 & 0.09 \\
WUE & 0.08 & 0.25 & 0.04 & -0.05 & 0.22 & 0.03 & -0.20 \\
\hline
\end{tabular}

'/ means not the input for the correlation test.

477

ecosystems or situations, EF usually has negative correlation with VPD while SWC positively correlates with GPP, LUE, $\lambda$ ET and EF.

The total effects were further decomposed into direct and indirect effects using path analysis. Table 4 shows the direct effects of environmental variables on the target variables. GPP, $\lambda E T$ and WUE are mainly controlled by radiation (either PAR or Rn-G). Once normalizing for different radiation as in LUE or EF variables the most important factor was Ta. CI had significant positive direct effects on all target variables GPP, LUE, $\lambda E T$, EF and WUE. That means that an increase in CI while maintaining the rest of considered variables fixed will produce a net increase in GPP, LUE, ET and EF. Based on this when incorporating CI into the models, we should consider that CI will increase GPP and ET (see Eq. (9) and (10)). Considering the whole year, the effects of CI on GPP, LUE and WUE are stronger than on $\lambda \mathrm{ET}$ and EF. It is possible that the effect of CI on transpiration is masked by evaporation from soil and intercepted water, which are insensitive to CI. When considering $\lambda \mathrm{ET}^{*}$ and $\mathrm{EF}^{*}$, to minimize the effect of evaporation of intercepted water and soil water, CI had stronger direct effects. This agrees with the land surface modeling results by Davin and Seneviratne (2012), which show that CI mainly influences transpiration and has limited impacts on evaporation from the intercepted water and soil. This finding further supports our modeling approach, which incorporates CI into the transpiration module only. Variables related to light harvesting by canopies (PAR and LAI) were the dominant factors regulating GPP. The top soil moisture (SWC) has very limited effects on GPP. For LUE, Ta was the important factor with a positive correlation, which emphasizes the sensitivity of this ecosystem to temperature. After Ta, LAI had also a positive effect while VPD reduced LUE. CI ranked as the fourth most important factor to influence LUE with a positive response. Similar to GPP, SWC had very weak effects on LUE. It is possible that the deep rooting system of the beech forest enables sufficient water supply even though water in the top soil is depleted (Wu et al., 2012). From these findings, we can conclude that the GPP and LUE of this high latitude ecosystem are controlled by radiation and temperature. For $\lambda E T$, CI had a weaker but still significant influence considering the whole year. As expected, $\mathrm{CI}$ had stronger impacts on $\lambda \mathrm{ET}^{*}$ during the growing season and in periods of high VPD. When normalizing $\lambda \mathrm{ET}$ by the available energy (Rn-G), Ta was the dominant factor with a positive effect on EF, followed by LAI and SWC. During the growing season, CI became the major controlling factor for EF*.

In our site, after accounting for energy, Ta and CI are the main factors to influence WUE. WUE increased in response to increases in Ta and CI. This is different from water-limited ecosystems, where increases in Ta tend to decrease WUE (Stroosnijder et al., 2012) and diffuse PAR tends to compensate for this effect (Gu et al., 2002; 
Rocha et al., 2004). However, higher VPD reduces GPP, LUE and $\lambda E T$ and EF due to the strong stomatal control.

506 These findings are helpful to refine parsimonious models for the simulation of GPP and ET. For instance, SWC

507 of the top soil could not be the necessary input for GPP simulation, since it has weak impacts on GPP.

508 Table 4. The direct effects from environmental factors to target variables

\begin{tabular}{cccccccc}
\hline Direct effects & CI & Ta & PAR & Rn-G & LAI & VPD & SWC \\
\hline GPP & 0.19 & 0.07 & 0.82 & $/$ & 0.44 & -0.17 & 0.02 \\
LUE & 0.31 & 0.58 & 0.20 & $/$ & 0.47 & -0.42 & -0.02 \\
$\lambda$ ET & 0.03 & 0.14 & $/$ & 0.51 & 0.50 & -0.05 & 0.11 \\
$\lambda$ ET $^{*}$ & 0.12 & 0.01 & $/$ & 0.67 & 0.25 & 0.00 & 0.18 \\
EF & 0.02 & 0.70 & $/$ & -0.35 & 0.46 & -0.30 & 0.08 \\
EF* & 0.25 & 0.23 & $/$ & -0.29 & 0.20 & -0.14 & 0.22 \\
WUE & 0.32 & 0.30 & 0.76 & -0.46 & -0.12 & -0.24 & -0.20 \\
\hline
\end{tabular}

509

510

511

512

513

514

515

516

517

518

$\mathrm{ET}^{*}$ and $\mathrm{EF}^{*}$ are for conditions ( $\mathrm{LAI}>2$ and $\mathrm{VPD}>3.5 \mathrm{hPa}$ ). '/' means not the input for path analysis.

The indirect effects describe how CI influences ecosystem carbon and water fluxes through other intermediate environmental variables over the whole year or the growing season, as shown in Table 5 . Over the year, CI mainly interacts with variables related to the radiation transfer (PAR, Rn-G and LAI) to reduce GPP and $\lambda E T$, respectively. After these radiation variables, Ta and VPD have been shown to deliver major indirect effects from CI to GPP, LUE, $\lambda E T$ and EF. Higher CI over the year decreases Ta, decreasing in turn LUE and EF, but CI also reduces VPD, which has positive effects on LUE and EF. For WUE, the effects of CI mainly go through PAR, Rn-G and VPD. It should be also noticed that the paths through SWC are very weak or not significant.

Table 5. The indirect effects from CI through other environmental factors to target variables

\begin{tabular}{ccccccc}
\hline Indirect effects from CI via: & Ta & PAR & Rn-G & LAI & VPD & SWC \\
\hline GPP & -0.02 & -0.63 & $/$ & -0.12 & 0.11 & 0.00 \\
LUE & -0.18 & -0.16 & $/$ & -0.13 & 0.27 & 0.00 \\
$\lambda E T$ & -0.03 & $/$ & -0.28 & - & 0.03 & - \\
$\lambda$ ET $^{*}$ & 0.00 & $/$ & -0.36 & 0.04 & 0.00 & - \\
EF & -0.19 & $/$ & 0.19 & -0.05 & 0.15 & - \\
EF* & -0.03 & $/$ & 0.14 & 0.02 & 0.06 & - \\
WUE & -0.06 & 0.28 & -0.59 & - & 0.14 & -0.01 \\
\hline
\end{tabular}

519

520

521

522

523

524

525

526

ET* and $\mathrm{EF}^{*}$ are for conditions (LAI $>2$ and VPD > $3.5 \mathrm{hPa}$ ). '/' means not the input for path analysis; '-' means the path analysis is not significant.

\subsection{Joint Gross Primary Productivity and Evapotranspiration modeling}

Based on path analysis, a parsimonious GPP and ET model was developed for the site. Since SWC was not a significant factor influencing GPP in the path analysis, the soil moisture constraint was excluded in the GPP and transpiration modeling but not for soil evaporation. The optimized parameter values increased, as shown in the Table 2. $\varepsilon_{\max }$ increased from 2.97 to 4.29 and $\alpha_{c}$ increased from 1.32 to 2.60 . The increase of parameter values 
527 is similar to that in Wang et al. (2015). In their study, CI was incorporated into the MODIS LUE algorithm and 528 after optimization, $\varepsilon_{\max }$ changed from 1.12 to 3.87 in a similar mixed deciduous broadleaf and evergreen needle 529 forest as this study. The value of 2.60 for $\alpha_{c}$ is also reasonable, considering for forests under totally diffuse 530 radiation conditions. Depending on the land conditions, $\alpha_{c}$ can reach a value of up to 3.62 in grass and forest 531 (Lhomme, 1997).

532 The model performance of GPP and $\lambda E T$ with and without CI was compared in Figure 3 during the calibration 533 and validation periods. It can be seen that with CI, the skills of both GPP and ET models improved. During the 534 calibration period, as shown in Figure 3 (a), RMSE of the simulated GPP decreased from 1.55 to $1.34 \mathrm{~g} \cdot \mathrm{C} \cdot \mathrm{m}^{-2} \cdot \mathrm{d}^{-1}$ 535 (RMSE reduced 13.25\%). $\mathrm{R}^{2}$ increased from 0.93 to 0.95 . Additionally, the bias was reduced from $-7.09 \%$ to $5364.14 \%$. During the validation period, as shown in Figure 3 (b), RMSE of simulated GPP reduced from 1.64 to $5371.45 \mathrm{~g} \cdot \mathrm{C} \cdot \mathrm{m}^{-2} \cdot \mathrm{d}^{-1}$ (RMSE reduced $11.68 \%$ ). $\mathrm{R}^{2}$ improved from 0.92 to 0.94 . The bias changed from $-5.59 \%$ to $5382.58 \%$. Further, we compared the improvement of the simulation performance between the whole period and the 539 growing season. The RMSE of the simulated GPP during the whole period decreased from 1.59 to $1.39 \mathrm{~g} \cdot \mathrm{C} \cdot \mathrm{m}^{-}$ $540 \quad{ }^{2} \cdot \mathrm{d}^{-1}$ (RMSE reduced $12.58 \%$ ) and $\mathrm{R}^{2}$ increased from 0.93 to 0.94 . While during the growing season, the RMSE 541 dropped from 2.37 to $2.06 \mathrm{~g} \cdot \mathrm{C} \cdot \mathrm{m}^{-2} \cdot \mathrm{d}^{-1}$ (by $13.08 \%$ ) and $\mathrm{R}^{2}$ increased from 0.68 to 0.73 . It can be seen that there is 542 more improvement in the growing season.

543 For $\lambda E T$, during the calibration period as shown in Figure 3 (c), when incorporating CI, the RMSE of simulated $544 \lambda$ ET from the PT-JPL model decreased from 17.03 to $14.39 \mathrm{~W} \cdot \mathrm{m}^{-2}$ (by $15.50 \%$ ). $\mathrm{R}^{2}$ increased from 0.85 to 0.87 . 545 The bias was reduced from $4.94 \%$ to $1.08 \%$. During the validation period, shown in Figure 3 (d), the RMSE was 546 reduced from 15.79 to $14.50 \mathrm{~W} \cdot \mathrm{m}^{-2}$ (by $8.16 \%$ ). $\mathrm{R}^{2}$ improved from 0.86 to 0.87 , while the bias was reduced from $5475.20 \%$ to $0.09 \%$. We also found for the whole period, the RMSE dropped from 16.09 to $14.44 \mathrm{~W} \cdot \mathrm{m}^{-2}$ (by 548 10.25\%), while during the growing seasons, the RMSE decreased from 19.08 to $16.89 \mathrm{~W} \cdot \mathrm{m}^{-2}$ (by $11.47 \%$ ). Both 549 GPP and $\lambda$ ET simulation improves when incorporating CI into the models, especially during the growing season. 550 The improvement of GPP simulations is more significant than that of $\lambda E T$. This agrees with the results from the 551 statistical path analyses, which showed a higher effect of diffuse PAR on GPP than on $\lambda E T$. CI has stronger 552 effects during the growing season $\left(\lambda \mathrm{ET}^{*}\right)$ than the effects during the whole period $(\lambda \mathrm{ET})$. The higher sensitivity 553 of GPP to $f_{\text {diff }}$ than for $\lambda$ ET has been also found in other studies (Mo and Liu, 2001; Knohl and Baldocchi, 2008; 554 Oliveira et al., 2011). 
(a)

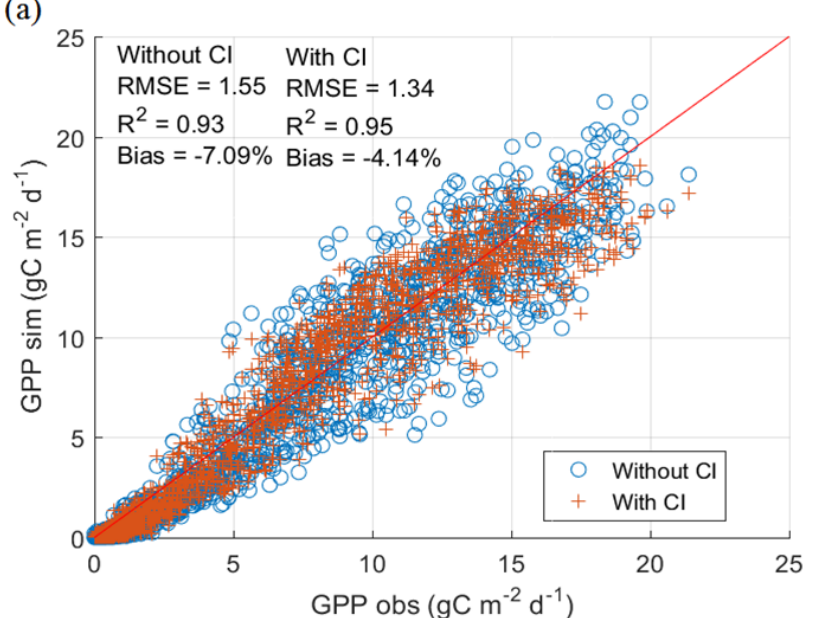

(c)

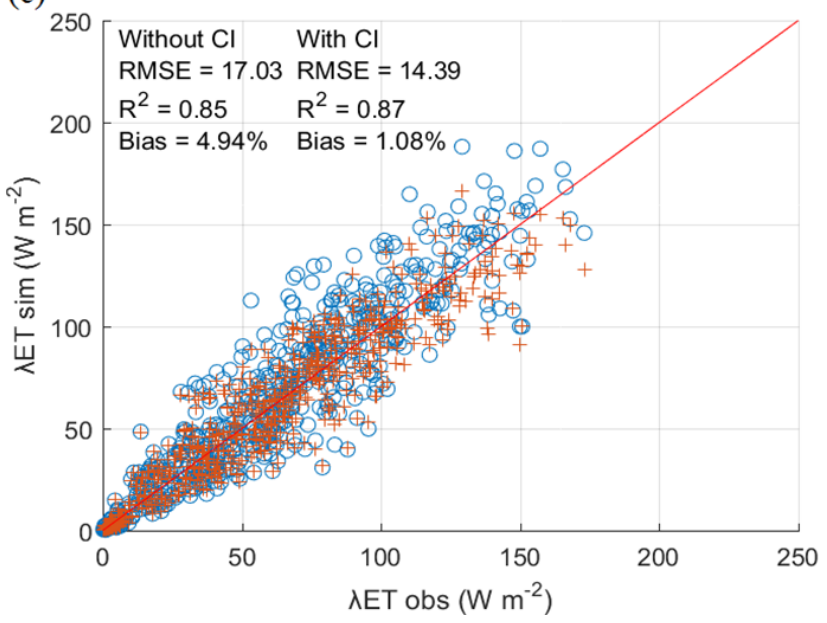

(b)
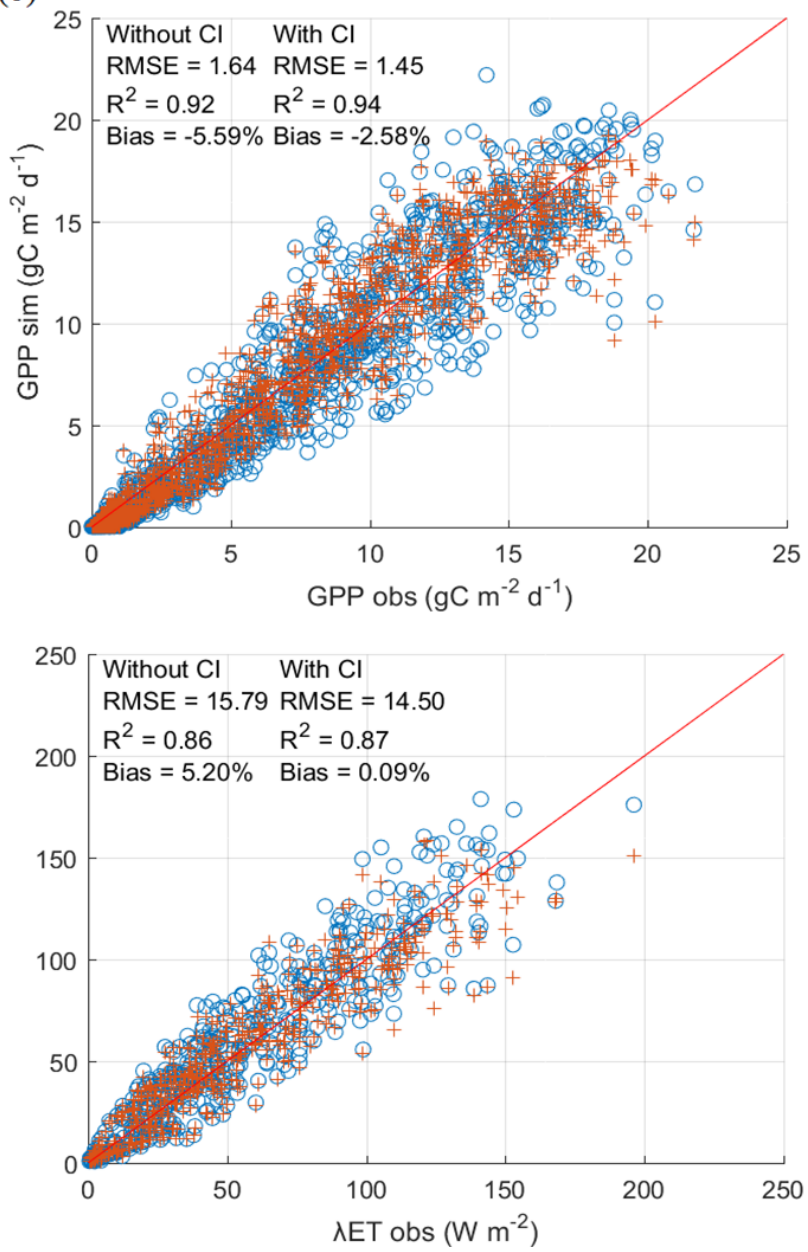

555

Figure 3. Scatter plots of the simulated and observed GPP (a: calibration, b: validation) and $\lambda$ ET (c: calibration, $\mathrm{d}$ : validation). The red dots are simulation with CI and the blue circles are the simulation without CI.

To understand under which environmental conditions there is a larger improvement of simulation performance, we stratified the improvement in model errors, $\triangle \mathrm{RSME}$ / MEAN, by levels of CI, Ta, VPD, LAI, PAR or Rn-G, and also assessed the effect of phenology by considering the day of the year (Figure 4). $\triangle \mathrm{RSME}$ is equal to $\mathrm{RSME}_{\text {without CI }}-\mathrm{RMSE}_{\text {with CI}}$. For different levels of CI, the RMSE for both GPP and $\lambda E T$ simulation decreased after including CI (Figure 4 (a) and (g)) with larger improvements for extreme CI values (e.g. sunny or completely overcast). While for median CI conditions, the improvement is lower. This is because in the simulation without CI, the optimized $\varepsilon_{\max }$ (Eq. 4) and $\alpha_{c}$ (Eq. 7) tend to represent median CI conditions, as a compromise that tends to be low in high diffuse fraction conditions and high in low diffuse fraction conditions. In the simulation with CI, $\varepsilon_{\max }$ (Eq. 9) and $\alpha$ (Eq. 10) were parameterized with CI and the simulation performs well in high and low diffuse radiation conditions. As for temperature shown in Figure 4 (b) and (h), under low temperatures the model improvements when incorporating CI are lowest, since both $\lambda E T$ and GPP are low. For VPD, both the simulated GPP and $\lambda E T$ improve at all levels and the improvements of $\triangle \mathrm{RSME}$ at all levels are similar. However, as for $\triangle \mathrm{RSME} / \mathrm{MEAN}$ shown in Figure 4 (c) and (i), the $\lambda E T$ improvements are larger for high VPD parts and GPP improvements are larger in the low VPD parts. This is due to that with low VPD, 
potential evapotranspiration was partitioned more into evaporation from intercepted water than transpiration, according to Eq. (6) and (7). The model incorporates CI only into the transpiration module. This results in 574 limited improvement of $\lambda$ ET in the low VPD part. However, the GPP improvements of $\triangle$ RSME for all levels are similar. The MEAN value of GPP is low. This leads to the high value of $\triangle$ RSME / MEAN in Figure 4 (c). For LAI, as shown in Figure 4 (d) and (j), improvements could be seen with different levels of LAI. For radiation (Figure $4(\mathrm{e})$ and $(\mathrm{k})$ ), the simulation improvements for GPP and $\lambda \mathrm{ET}$ are similar to VPD. This is due to that high VPD and low radiation (low PAR and Rn-G) are concurrent. For different days of the year as shown in Figure 4 (f) and (l), the largest improvements occurred in the growing season from May to October. Generally, both GPP and $\lambda$ ET simulation improvements occur in the growing season, which coincides with higher temperatures and larger incoming PAR.
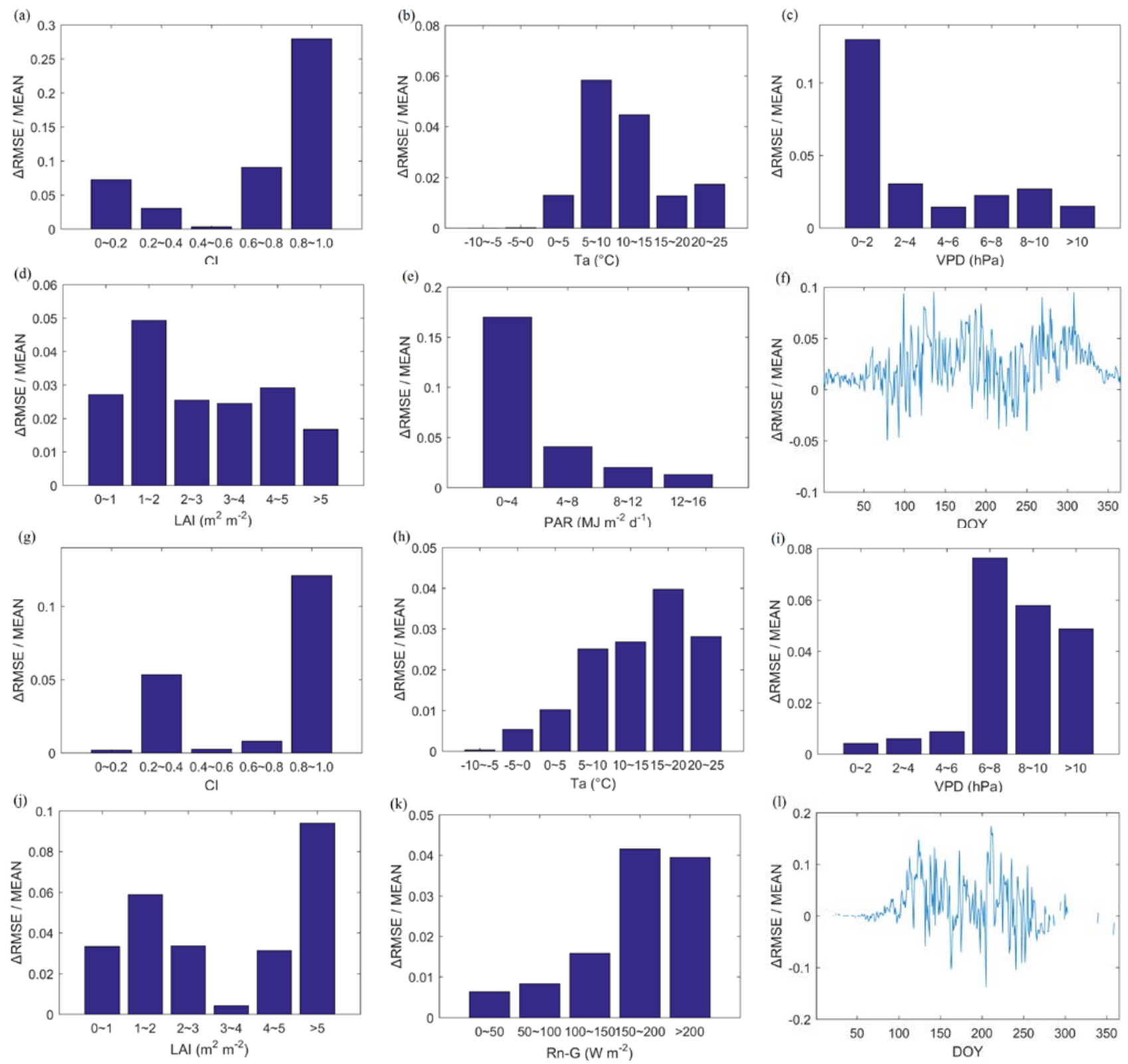
605

606

Figure 4. The comparison of modeling performance without and with CI. The y-axis is the $\triangle$ RMSE/MEAN. The positive value indicates the simulation improvement, while the negative value means the simulation degradation. (a f) are for the GPP. (g l) are for $\lambda E T$. (a) and (g) show the modeling improvement with various CI levels. (b) and (h) are for Ta. (c) and (i) are for VPD. (d) and (j) correspond to various LAI levels. (e) and (k) are for different PAR or Rn-G levels. (f) and (l) show the different day of year.

Comparison with sap flow measurements (Figure 5) shows that measurements fit slightly better with the simulation with CI (red dots) than the simulation without CI (blue dots). The limited improvement is due to model and observation uncertainties. For example, in the PT-JPL model, the relative surface wetness $\left(f_{\text {wet }}=\right.$ $\mathrm{RH}^{4}$ ) was used to partition the evaporation from the intercepted rainfall and canopy transpiration. This empirical formula might not be transferable without calibration to all sites and $f_{\text {wet }}$ may not accurately partition evaporation from the intercepted rainfall and canopy transpiration. Additionally, there are uncertainties related to measurements of sap flow and upscaling sap flow data to the ecosystem level. However, the purpose is to compare Ec and sapflow and to check whether there is an improvement of simulated Ec. With the current data set, after incorporating CI into the model, the simulated transpiration improved as shown by the $\mathrm{R}^{2}$ increasing from 0.60 to 0.64 . This indicates that including CI could improve the simulation of transpiration. By comparing the simulated $\lambda E T$ of the same dates, the improvement for $\lambda \mathrm{ET}$ simulation with $\mathrm{CI}$ is small. After incorporating CI, the RMSE of $\lambda$ ET decreased from 13.99 to $13.73 \mathrm{~W} \cdot \mathrm{m}^{-2}$. For $\mathrm{R}^{2}$, the simulations with and without CI have the same value of 0.92 (results not shown). This indicates incorporating CI may have limited improvement for total ET, but the improvements on Ec are larger.

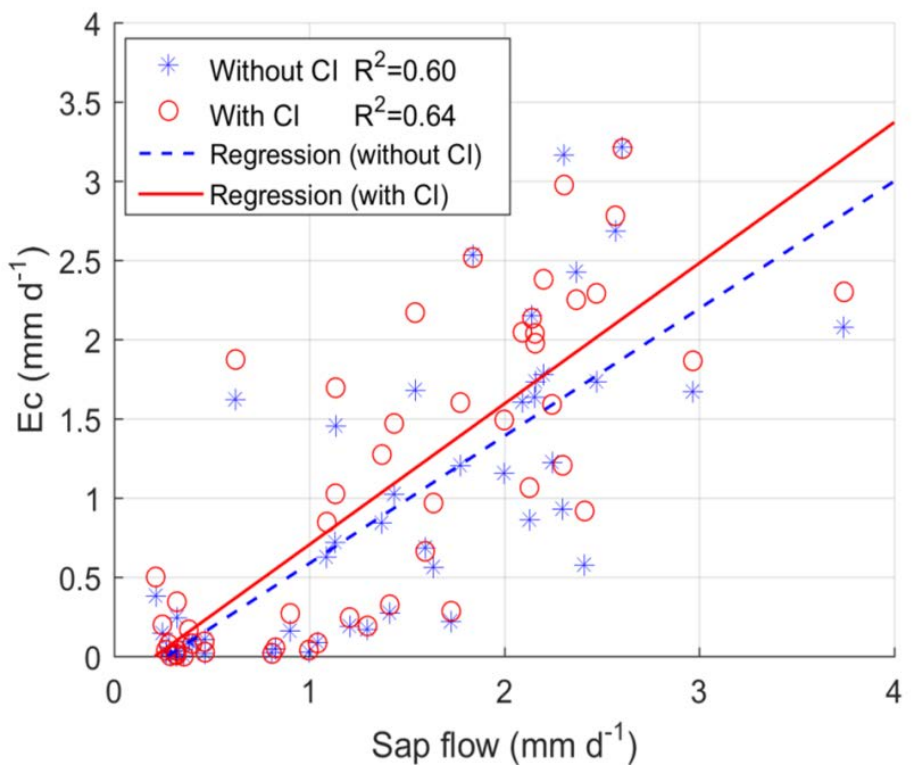

Figure 5. The scatterplot to evaluate transpiration (Ec) with sap flow data (blue dots are simulation without CI and red circles are simulation with CI)

4.3 Global sensitivity analysis (GSA) 
In this section, we aim to quantify the influence that CI has on GPP, $\lambda \mathrm{ET}$ and $\lambda \mathrm{Ec}$ and how it varies across different months. The first order sensitivity represents the contribution of model forcing environmental variables to GPP, $\lambda E T$ and $\lambda E c$ (Figure 6 ). For GPP, $\lambda E T$ and $\lambda E c$, their variations are mainly regulated by the radiation (PAR or Rn). This agrees with the direct effects from path analysis results, as shown in Table 4, indicating that the ecosystem of this flux site is radiation controlled (van Dijk et al., 2005; Lagergren et al., 2008). Moreover, similar to the direct effects from the path analysis, the effects of CI on GPP, $\lambda E T$ and $\lambda E c$ are of similar magnitude as those from VPD, air temperature and NDVI (which indicates LAI and phenology). Therefore, the match between the direct effects revealed by path analysis and the first order sensitivity determined with GSA confirms that the joint GPP and ET model can capture the major processes in this ecosystem. Furthermore, GSA analysis also shows that sensitivities of GPP, $\lambda E T$ and $\lambda$ Ec vary substantially across different months (Fig.5). CI had very limited contributions to the variability of GPP, $\lambda \mathrm{ET}$ and $\lambda \mathrm{Ec}$ in winter. The fact that there is a small effect in winter, i.e. when the beech trees are without leaves, is due to the fact that there are ca. $20 \%$ conifers in the forest with a small contribution to the annual GPP. However, CI contributed more to the daily variability of $\mathrm{GPP}, \lambda \mathrm{ET}$ and $\lambda \mathrm{Ec}$ during the growing season, similar to the findings in our data driven analysis (Table 4) that showed that $\lambda \mathrm{ET}^{*}$ and $\mathrm{EF}^{*}$ were more sensitive to the CI than $\lambda \mathrm{ET}$ and $\mathrm{EF}$ for the whole years. During the growing season (from May to October), CI contributed to $11.88 \%$, 3.04\% and $7.78 \%$ of the total variability in GPP, $\lambda \mathrm{ET}$ and $\lambda \mathrm{Ec}$, respectively. The contribution from CI to GPP is the highest, followed by $\lambda \mathrm{Ec}$. The contribution to $\lambda \mathrm{ET}$ is less than that to $\lambda \mathrm{Ec}$ is due to soil evaporation is not sensitive to $\mathrm{CI}$.
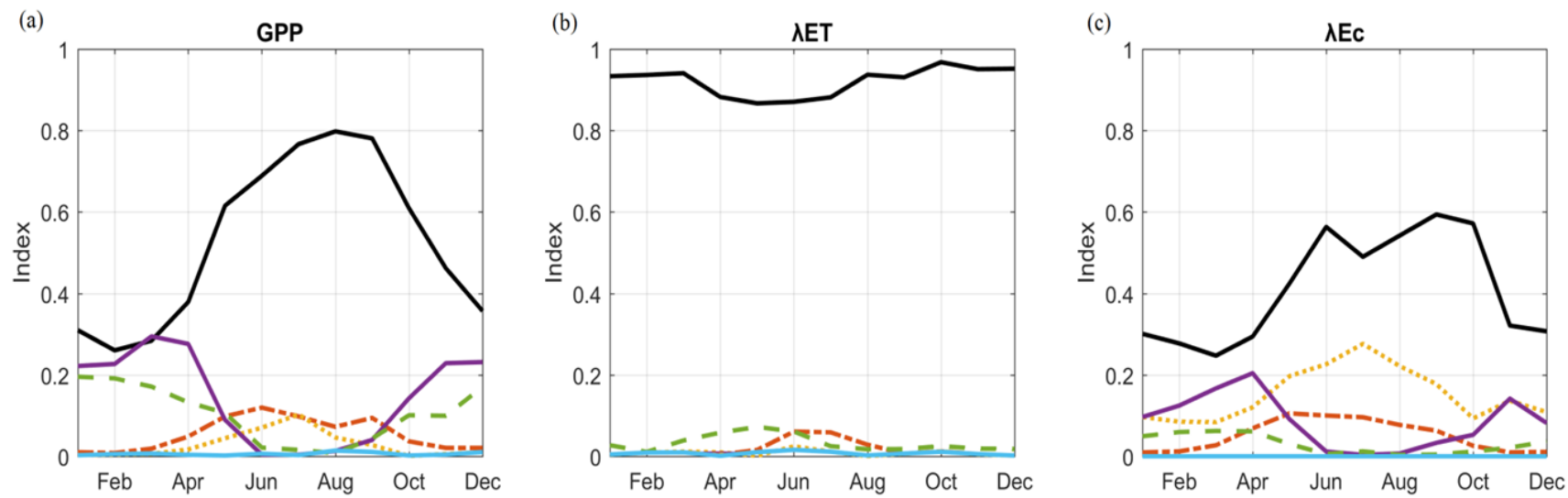

\begin{tabular}{lllllll}
\hline -PAR(GPP) or Rn-G (ET and ETc) & $---\mathrm{Cl}$ & $\cdots \cdot \cdot \mathrm{VPD}$ & $-\mathrm{NDVI}$ & $--\mathrm{Ta}$ & $-\mathrm{SZA}$
\end{tabular}

625

626

627

628

629

630

631

632

633

634
Figure 6. The first order Sobol' sensitivity index for the simulated GPP (a), $\lambda E T$ (b) and $\lambda E c$ (c) for each month. The variables are radiation components (PAR for GPP, Rn-G for $\lambda E T$ and $\lambda E c$ ), CI, VPD, NDVI, Ta and SZA.

The second order sensitivity reveals interactions between the environmental variables and their joint effects on the daily variability of GPP, $\lambda \mathrm{ET}$ and $\lambda \mathrm{Ec}$. For GPP, as shown in Figure 7 (a), the clearest interaction is between PAR and NDVI, indicating how changes in APAR determine GPP. For $\lambda E T$, as shown in Figure 7 (b), the strongest interaction is again for energy and temperature variables: $\mathrm{Rn}$ and Ta. Second order sensitivities of $\lambda \mathrm{Ec}$ are shown in Figure 7 (c). Compared to GPP and $\lambda E T$, the second order sensitivities of $\lambda E c$ are higher indicating more interactions among environmental variables to regulate the transpiration. The highest interaction for $\lambda E c$ is between Rn and VPD. CI mainly interacts with radiation (PAR or Rn-G) to control the GPP, $\lambda E T$ and $\lambda E c$, 
reflecting this ecosystem is radiation limited. This result also matches well with the path analysis in Table 5, which CI has highest indirect effects on GPP, $\lambda \mathrm{ET}$ and $\lambda \mathrm{ET}^{*}$ through PAR or Rn-G. NDVI is the second most important variable to interact with CI to jointly influence GPP. Similarly, in Table 5, LAI ranked as the second important variable to deliver the indirect effects from CI to GPP. As for $\lambda E T$ and $\lambda E c$, VPD and NDVI are important variables after Rn-G. Compared to Table 5, the indirect effects from CI through LAI and VPD to $\lambda E T$ and $\lambda \mathrm{ET}^{*}$ are also significant. These results indicate that with potentially increasing levels of aerosols and diffuse PAR over the growing season in the future, the WUE, LUE and EF will increase in principle, but the magnitude of the enhancement will depend on the interplay between VPD and Ta.
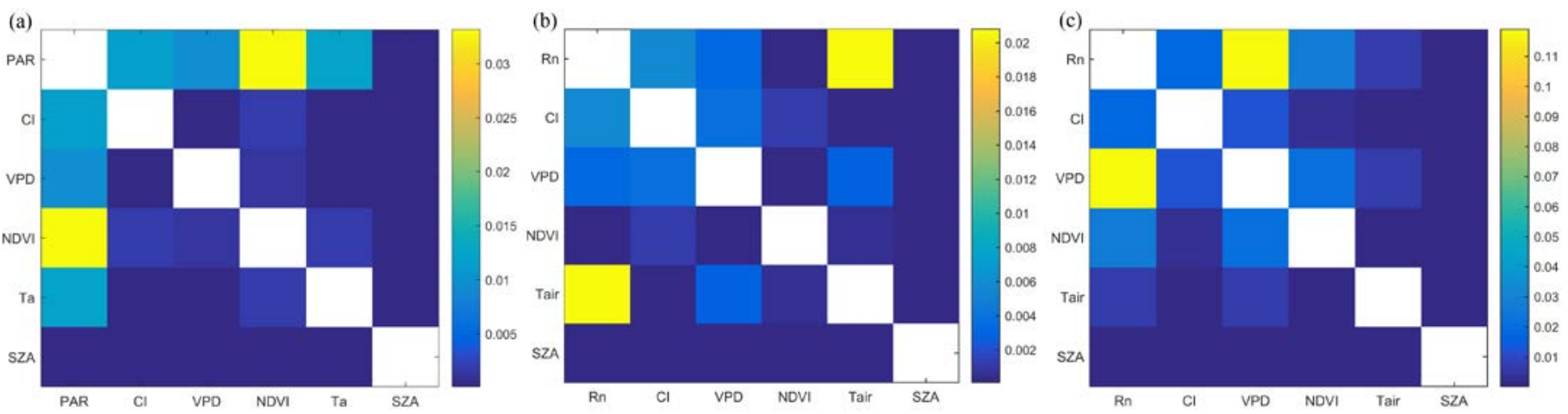

Figure 7. The second order Sobol' sensitivity index for the simulated GPP (a), $\lambda E T$ (b) and $\lambda E c$ (c) for the whole year

\subsection{Potential mechanism for diffuse PAR to influence GPP and ET of the Sorø beech forest site}

Several mechanisms have been reported to explain the impacts of $f_{\text {diff }}$ on GPP and ET. First, for the same levels of PAR, diffuse PAR penetrates deeper into the canopies than direct PAR, and hence makes the vertical distribution of PAR more even throughout forest canopies. Photosynthesis in the lower part of the canopy will be stimulated by the increased diffuse PAR (Hollinger et al., 1994; Weiss, 2000; Oliphant et al., 2011). Second, under clear-sky conditions, PAR is mainly direct, resulting in the photosynthesis of sunlit leaves being saturated, whereas the photosynthesis rates of shaded leaves are constrained by the limited intercepted radiation. On cloudy days, solar radiation is scattered by clouds in addition to atmospheric aerosols and the proportion of diffuse PAR is high. The saturation effects of the sunlit leaves will be reduced ( $\mathrm{Gu}$ et al., 2002). Furthermore, photosynthesis and WUE may also benefit from reduced water and heat stress of plants when going from sunny and higher PAR conditions to diffuse conditions (Gu et al., 2002; Lloyd et al., 2002; Steiner and Chameides, 2005; Urban et al., 2012), especially for water limited ecosystems. Another possible reason for the high photosynthesis rate with diffuse PAR is a change in spectral composition. Diffuse PAR has a higher ratio of blue to red bands than direct PAR, which could stimulate photochemical reactions and stomatal opening (Urban et al., 2012; Cheng et al., 2015).

It has been shown how in temperature-limited systems at high latitudes, incoming longwave radiation ( $\left.\mathrm{LW}_{\text {in }}\right)$ under cloudy conditions is an important source of energy for snow melting by increasing the land surface 
temperature (Juszak \& Pelliciotti, 2013). We hypothesize that for a given total amount of PAR, increasing diffuse fraction of PAR is associated with increased $L W_{\text {in }}$ from clouds and aerosol, which should increase both GPP and ET in temperature-limited conditions. To further explore this, the longwave radiative budget was checked controlling for PAR (Figure 8 (a)). With more clouds, $\mathrm{LW}_{\text {in }}$ increased significantly $(\mathrm{p}<0.05$ ) for similar incoming PAR. A clear effect of canopy warming (surface temperature, Ts) via longwave radiative budget can be seen in Figure 8 (b). In this temperature-limited ecosystem, increases in surface temperature (e.g. canopy temperature) should enhance photosynthesis. For the air temperature ( $\mathrm{Ta}$ ), we can also see the temperature increase, but the increase of Ta is lower than that of Ts. Moreover, we also check the difference of VPD in diffuse and direct radiation conditions, as shown in Figure 8 (d). It can be seen that VPD in diffuse and direct radiation conditions was not significantly different within similar PAR levels. Even though in the long-term dynamics (e.g. path analysis) lower VPD was linked to higher GPP and ET when controlling for PAR, changes in VPD are not significant. Therefore, it can be seen that there is a possible mechanism in this ecosystem that increase of long wave incoming due to more clouds could increase the surface temperature and further enhance the photosynthesis rate. This leads to larger GPP and $\lambda \mathrm{Ec}$.

(a)
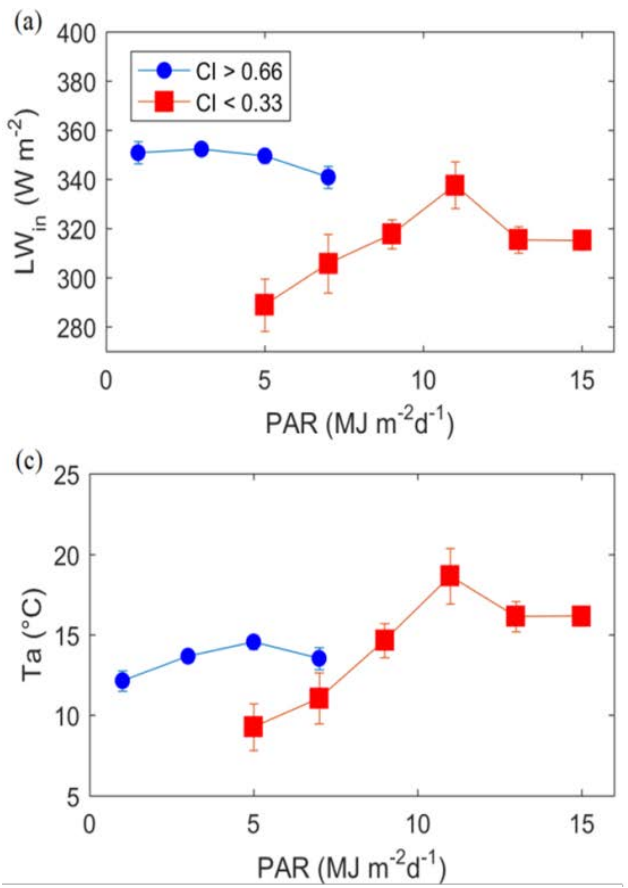

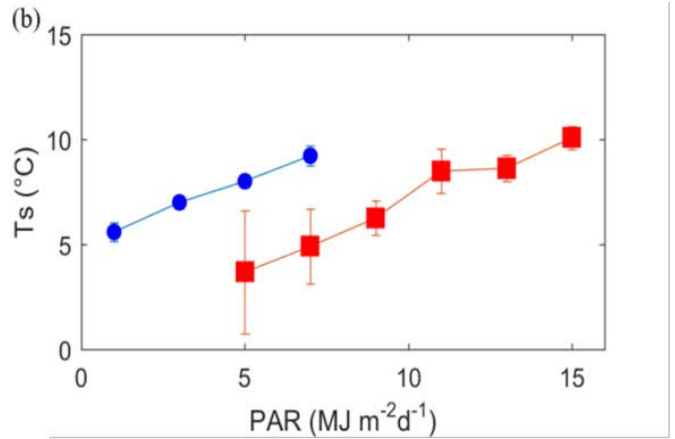

(d)

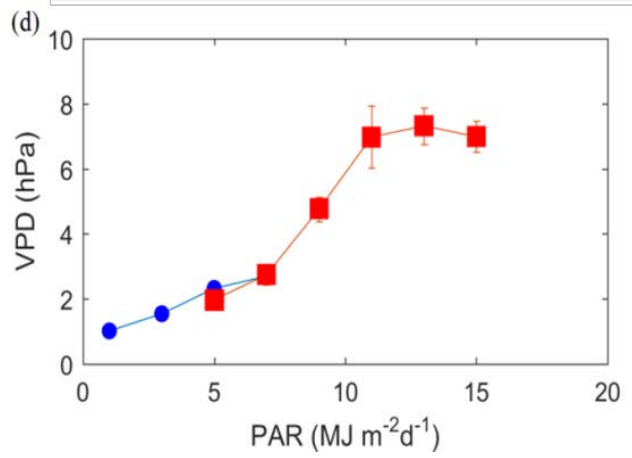

678

679

680

681

682

683

684

Figure 8. Responses of $\mathrm{LW}_{\text {in }}$ (a), canopy temperature Ts (b) and VPD (c) to various levels of PAR for predominantly diffuse light condition (blue, $\mathrm{CI}>0.66$ ) and predominantly direct light conditions (red, $\mathrm{CI}<0.33$ ). The points represent the mean value for specific incoming PAR interval and the error bar represent the significance level at $\mathrm{p}<0.05$ ). To exclude the effects from phenology and obtain canopy temperature Ts, comparison was conducted with NDVI more than 0.75 .

4.5 Comparison between CI and $f_{\text {diff }}$ 
This study assumes that $f_{\text {diff }}$ can be characterized by CI. The reason to use CI is its longer temporal availability (2002-2012) at the Soroe flux site, while the observed $f_{\text {diff }}$ was available only from 2004. Although previous studies in the Netherlands and in tropical forest ecosystems have proven a strong relationship between $f_{\text {diff }}$ and CI (Spitters et al., 1986; Butt et al., 2010), this relationship might be different in high latitude areas. We performed a statistical correlation test and model based analysis to check the difference between CI and $f_{\text {diff. Figure }} 9$ (a) shows that $\mathrm{CI}$ and $f_{\text {diff }}$ are highly correlated $(\mathrm{R}=0.94)$. However, there is significant scatter when using the two fractions at the daily time scale. This may be due to that in this study, we assume the PAR is equal to the half of solar shortwave radiation and CI is actually calculated based on the whole range of solar radiation. However, $f_{\text {diff }}$ is based on the observed diffuse and total PAR on the ground. The effects of scattering are wavelength dependent, therefore CI and $f_{\text {diff }}$ may behave differently. Additionally, in the atmosphere, there are two types of wavelength dependent scattering: Rayleigh and Mie scattering. With different types of scattering, the relationship between CI and $f_{\text {diff }}$ may be influenced. However, even though the relationship between CI and $f_{\text {diff }}$ shows some scatter, when we use these two indices as indicators of diffuse radiation in our modeling framework, they show very similar simulation results, as shown in the Taylor Diagram of Figure 9 (b). The simulation results are very similar. We therefore conclude that CI and $f_{\text {diff }}$ are very similar and any of these quantities could be used to represent the diffuse PAR in this region.

(a)

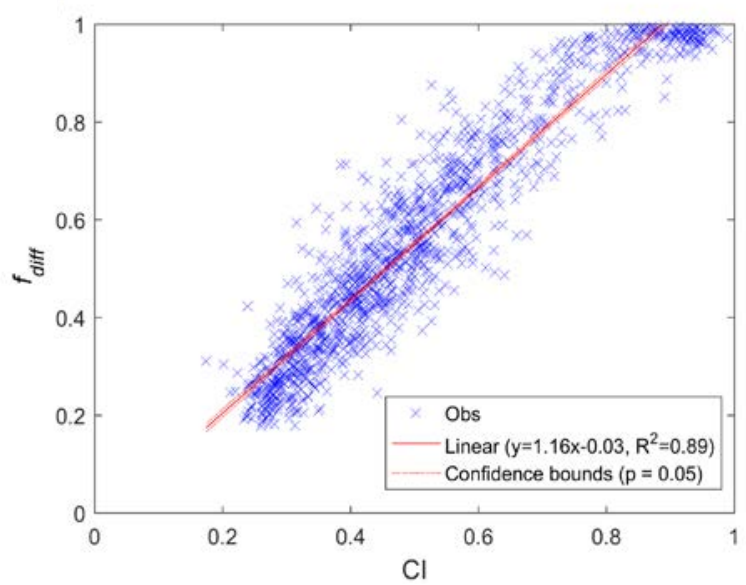

(b)

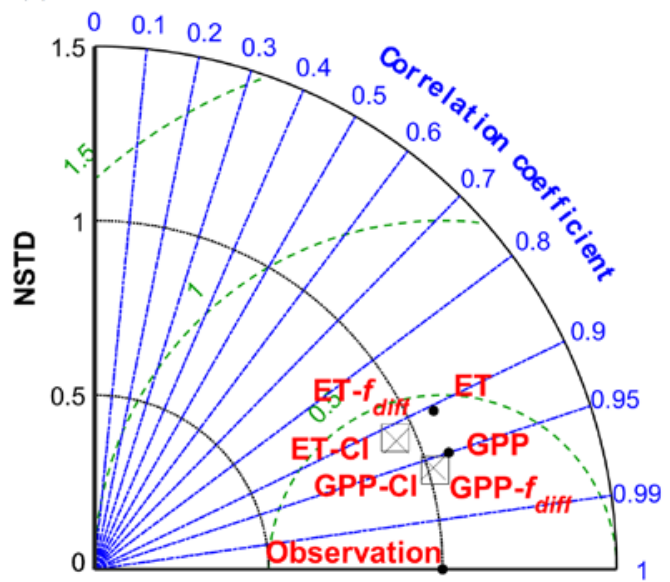

702

703

704

705

706

707

708

709

710

711

712

Figure 9. Comparison between $f_{\text {diff }}$ and CI from 2004 to 2012. (a) the correlation test between CI and $f_{\text {diff }}$ (b) Taylor diagram comparing the GPP and ET modeling performance with CI (X) and $f_{\text {diff }}$ (square) and without the diffuse fraction (dot).

\subsection{Other factors that may potentially change responses of GPP and ET to diffuse PAR}

This study evaluated the impact of diffuse PAR on GPP and ET, and assessed the interactions between CI and other biophysical environmental variables to jointly regulate GPP and ET. Due to data availability and model complexity, only environmental variables i.e. PAR, Rn-G, LAI, VPD, Ta and SWC were considered in the analysis. Besides these biophysical variables, other variables providing an accurate estimate of the overall fraction of absorbed PAR e.g. leaf inclination angle, leaf optical parameters (reflectance and transmittance) and 
leaf-clumping index could influence the impacts of CI on GPP and ET. For instance, Knohl and Baldocchi (2008) found a $20 \%$ increase in diffuse PAR effects, when the leaf inclination angle increased from 40 to 70 , using a canopy radiative transfer model. Variability in the orientation of leave surfaces also changes effects of diffuse PAR. Bonan (2002) suggested that the upper canopy leaves could utilize sunlight more efficiently when they have a near vertical orientation, while the lower foliage must almost be in a horizontal position. Knohl and Baldocchi (2008) highlighted that the clumped leave distribution could also have advantages for diffuse PAR. However, our study used top-down and parsimonious GPP and ET models and focused on the ecosystem scale. The impact of leaf properties throughout the whole canopy can thus not be analyzed in detail. The influence of diffuse PAR on evaporation of intercepted rainfall and soil water was also ignored. Diffuse PAR is more homogeneous than direct PAR. Diffuse PAR can penetrate deeper and radiation throughout the canopy and at the soil surface is more evenly distributed. This could contribute to not only higher transpiration rate but also more evaporation from soil and the intercepted water. According to Davin and Seneviratne (2012) the response of evaporation is less significant than the response of transpiration. This is also supported by our path analysis results. Therefore, in the PT-JPL model, CI was not incorporated in the parameterization of evaporation.

\section{Conclusion}

The effects of diffuse fraction of PAR on the carbon and water fluxes of a high latitude temperate deciduous forest ecosystem were evaluated using an 11-year (2002-2012) eddy covariance data set from a Danish flux site at Soroe. Using statistical analysis, this study identified that GPP, ET and WUE were mainly controlled by variables related with the radiation transfer in the canopy and net energy balance (PAR, LAI and Rn-G) while LUE and EF were primarily controlled by air temperature (Ta). This indicates that this beech forest ecosystem is radiation and temperature limited. Diffuse PAR, expressed by the Cloudiness Index (CI), had positive direct effects on GPP, LUE, ET, EF and WUE. In terms of indirect effects, CI mainly interacted with the radiation components in the canopy (PAR, Rn-G and LAI) to influence GPP and ET. Ta and VPD were the major intermediate variables to deliver the indirect influence from CI to LUE and EF. These results indicate that with potentially increasing levels of aerosols and diffuse PAR over the growing season in the future, the WUE, LUE and EF will increase in principle, but the magnitude of the enhancement will depend on the interplay between VPD and Ta.

We tested a joint ‘top-down' GPP and ET model, which combines a light use efficiency GPP model (Monteith et al, 1972) and Priestley-Taylor Jet Propulsion Laboratory ET model (Fisher et al., 2008). When incorporating CI into the simulations, the model performance for both GPP and ET improved with the RMSE of the daily GPP decreasing from 1.64 to $1.45 \mathrm{~g} \cdot \mathrm{C} \cdot \mathrm{m}^{-2} \cdot \mathrm{d}^{-1}(11.68 \%$ reduction) and the RMSE of the daily ET decreasing from 15.79 to $14.50 \mathrm{~W} \cdot \mathrm{m}^{-2}$ (8.16\% reduction). Based on a global sensitivity analysis (GSA), $11.88 \%, 3.04 \%$ and $7.78 \%$ of the variability of GPP, ET and transpiration, respectively, can be attributed to CI in the growing season from May to October. This proves that CI has largest impacts on GPP, followed by transpiration and finally ET, which results in higher WUE under diffuse fraction conditions. Even though the impact on ET is moderate, it was consistent and we found that most of the ET model improvements when incorporating CI could be linked to the transpiration component by comparing with sap flow measurements. 
To explain the mechanisms behind GPP and evapotranspiration enhancement with diffuse radiation for fixed levels of PAR, most previous studies have focused on variables affecting the fraction of absorbed PAR. We found that the longwave emission from clouds and aerosols plays an additional role in this high latitude ecosystem. Under diffuse conditions and for same incoming PAR levels, higher longwave emission contributes to higher air and canopy temperature increasing both GPP and transpiration. This highlights the importance of improving the description of the complete radiative transfer in canopies under diffuse and direct conditions in high latitude deciduous forests to model GPP and ET.

\section{Acknowledgement:}

The authors would like to thank the EU and (Centre for the development of Industrial Technology (CDTI), Innovation Fund Denmark (IFD) and Flanders Innovation \& Entrepreneurship (VLAIO)) for funding, in the frame of the collaborative international consortium FORWARD financed under the ERA-NET Cofund WaterWorks2015 Call. This ERA-NET is an integral part of the 2016 Joint Activities developed by the Water Challenges for a Changing World Joint Programme Initiative (Water JPI). We thank the editor and anonymous reviewers for their insightful comments and suggestions.

\section{References:}

Baldocchi, D.D., 2003. Assessing the eddy covariance technique for evaluating carbon dioxide exchange rates of ecosystems: past, present and future. Glob. Change Biol., 9(4), 479-492.

Bassow, S.L., Bazzaz, F.A., 1998. How environmental conditions affect canopy leaf-level photosynthesis in four deciduous tree species. Ecology, 79(8), 2660-2675.

Boegh, E., Poulsen, R.N., Butts, M., et al., 2009. Remote sensing based evapotranspiration and runoff modeling of agricultural, forest and urban flux sites in Denmark: From field to macro-scale. J. Hydrol., 377(3), 300-316.

Butt, N., New, M., Malhi, Y., et al., 2010. Diffuse radiation and cloud fraction relationships in two contrasting Amazonian rainforest sites. Agr. Forest. Meteorol., 150(3), 361-368.

Chen, J., Jönsson, P., Tamura, M., et al., 2004. A simple method for reconstructing a high-quality NDVI timeseries data set based on the Savitzky-Golay filter. Remote Sens. Environ., 91(3), 332-344.

Chen, Y., Xia, J., Liang, S., et al., 2014. Comparison of satellite-based evapotranspiration models over terrestrial ecosystems in China. Remote Sens. Environ., 140, 279-293.

Cheng, S. J., Bohrer, G., Steiner, A. L., et al., 2015. Variations in the influence of diffuse light on gross primary productivity in temperate ecosystems. Agr. Forest. Meteorol., 201, 98-110. 
Ciais, Ph, M. Reichstein, Nicolas Viovy, et al., 2005. Europe-wide reduction in primary productivity caused by the heat and drought in 2003. Nature 437, 7058: 529-533.

Davin, E. L., Seneviratne, S. I., 2012. Role of land surface processes and diffuse/direct radiation partitioning in simulating the European climate. Biogeosciences, 9(5), 1695-1707.

Donohue, R.J., Hume, I.H., Roderick, M.L., et al., 2014. Evaluation of the remote-sensing-based DIFFUSE model for estimating photosynthesis of vegetation. Remote Sens. Environ., 155, 349-365.

Dunn, A. L., Barford, C. C., Wofsy, S. C., et al., 2007. A long-term record of carbon exchange in a boreal black spruce forest: Means, responses to interannual variability, and decadal trends, Glob. Chang. Biol., 13, 577-590.

Ershadi, A., McCabe, M.F., Evans, J.P., et al., 2014. Multi-site evaluation of terrestrial evaporation models using FLUXNET data. Agr. Forest. Meteorol., 187, 46-61.

Fisher, J.B., Tu, K.P. Baldocchi, D.D., 2008. Global estimates of the land-atmosphere water flux based on monthly AVHRR and ISLSCP-II data, validated at 16 FLUXNET sites. Remote Sens. Environ., 112(3), 901-919.

García, M., Sandholt, I., Ceccato, P., et al., 2013. Actual evapotranspiration in drylands derived from in-situ and satellite data: Assessing biophysical constraints. Remote Sens. Environ., 131, 103-118.

Gu, L.H., Baldocchi, D., Verma, S.B., et al., 2002. Advantages of diffuse radiation for terrestrial ecosystem productivity. J. Geophys. Res.: Atmos.. 107, 4050.

Gu, L.H., Baldocchi, D.D., Wofsy, S.C., et al., 2003. Response of a deciduous forest to the Mount Pinatubo eruption: enhanced photosynthesis. Science 299, 2035-2038.

He, M., Ju, W., Zhou, Y., et al., 2013. Development of a two-leaf light use efficiency model for improving the calculation of terrestrial gross primary productivity. Agr. Forest. Meteorol., 173, 28-39.

Heald, C. L., Henze, D. K., Horowitz, L. W., et al. 2008. Predicted change in global secondary organic aerosol concentrations in response to future climate, emissions, and land use change. J. Geophys. Res.: Atmos., 113.D5.

Healy, K.D., Ricker, K.G., Hammer, G.L., Bange., M.P., 1998. Radiation use efficiency increases when the diffuse component of incident radiation is enhanced. Aust. J. Agric. Res. 49:665- 672.

Hollinger, D. Y., Kelliher, F. M., Byers, J. N., Hunt, J. E., McSeveny, T. M., Weir, P. L., 1994. Carbon dioxide exchange between an undisturbed old growth temperate forest and the atmosphere. Ecology, 75(1), 134-150.

Houborg, R., Anderson, M.C., Norman, J.M., Wilson, T., Meyers, T., 2009. Intercomparison of a 'bottomup'and 'top-down'modeling paradigm for estimating carbon and energy fluxes over a variety of vegetative regimes across the US. Agr. Forest. Meteorol., 149(11), 1875-1895.

Houborg, R.M. Soegaard, H., 2004. Regional simulation of ecosystem CO2 and water vapor exchange for agricultural land using NOAA AVHRR and Terra MODIS satellite data. Application to Zealand, Denmark. Remote Sens. Environ., 93(1), 150-167. 
814 Huxman, T.E., Turnipseed, A.A., Sparks, J.P., Harley, P.C., Monson, R.K., 2003. Temperature as a control over 815 ecosystem CO2 fluxes in a high-elevation, subalpine forest. Oecologia, 134(4), 537-546.

816 Ibrom, A., Jarvis, P.G., Clement, R., et al., 2006. A comparative analysis of simulated and observed 817 photosynthetic CO2 uptake in two coniferous forest canopies. Tree Physiol., Victoria- 26, 7: 845.

818 Impens, I., Lemur, R., 1969. Extinction of net radiation in different crop canopies. Theor. Appl. Climatol., 17, $819 \quad 403-412$.

820 Kanniah, K.D., Beringer, J., North, P. Hutley, L., 2012. Control of atmospheric particles on diffuse radiation and 821 terrestrial plant productivity: A review. Prog. Phys. Geog., 36(2), 209-237.

822 Knohl, A., Baldocchi, D. D., 2008. Effects of diffuse radiation on canopy gas exchange processes in a forest 823 ecosystem. J. Geophys. Res.: Biogeosci. 113.G2 .

824 Lagergren, F., Lindroth, A., Dellwik, E., et al., 2008. Biophysical controls on CO2 fluxes of three northern 825 forests based on long-term eddy covariance data. Tellus B, 60(2), 143-152.

826 Lhomme, J.P., 1997. A theoretical basis for the Priestley-Taylor coefficient. Bound-Lay. Meteorol., 82(2), 179827191.

828 Li, C.C., 1975. Path analysis-a primer. The Boxwood Press.

829 Lohammer T., Larsson S., Linder S. Falk S.O., 1980. FAST simulation models of gaseous exchange in Scots 830 Pine. Ecol. Bull., 32, 505-523.

831 McCallum, I., Wagner, W., Schmullius, C., Shvidenko, A., Obersteiner, M., Fritz, S. Nilsson, S., 2009. Satellite832 based terrestrial production efficiency modeling. Carbon balance and management, 4(1), 8.

833 Mercado, L.M., Bellouin, N., Sitch, S., Boucher, O., Huntingford, C., Wild, M., Cox, P.M., 2009. Impact of 834 changes in diffuse radiation on the global land carbon sink. Nature 458, 1014-1087.

835 Michel, D., Jiménez, C., Miralles, D. M., et al., E. F. Wood, and D. Fernández-Prieto, 2016. The WACMOS-ET 836 project - Part 1: Tower-scale performance of four observation-based evapotranspiration algorithms, Hydrol. 837 Earth Syst. Sci., 20, 803-822.

838 Miralles, D. G, Jiménez, C., Jung, M., et al., 2016. The WACMOS-ET project - Part 2: Evaluation of global land 839 evaporation data sets, Hydrol. Earth Syst. Sci., 20, 823-842.

840 Mo, X., Liu, S., 2001. Simulating evapotranspiration and photosynthesis of winter wheat over the growing 841 season, Agr. Forest. Meteorol., 109, 203-222.

842 Monteith, J.L., 1972. Solar radiation and productivity in tropical ecosystems. J. Appl. Ecol., 9(3), 747-766.

843 Mu, Q., Heinsch, F.A., Zhao, M., Running, S.W., 2007. Development of a global evapotranspiration algorithm 844 based on MODIS and global meteorology data. Remote Sens. Environ., 111(4), 519-536. 
845 Oliphant, A. J., Dragoni, D., Deng, B., et al., 2011. The role of sky conditions on gross primary production in a 846 mixed deciduous forest. Agr. Forest. Meteorol., 151(7), 781-791.

847 Oliveira, P.J., Davin, E.L., Levis, S., Seneviratne, S.I., 2011. Vegetation-mediated impacts of trends in global 848 radiation on land hydrology: a global sensitivity study. Glob. Change Biol., 17(11), 3453-3467.

849 Orgill, J.F., Hollands, K.G.T., 1977. Correlation equation for hourly diffuse radiation on a horizontal surface. Sol. 850 Energy, 19(4), 357-359.

851 Pilegaard, K., Hummelshøj, P., Jensen, N.O., Chen, Z., 2001. Two years of continuous CO2 eddy-flux 852 measurements over a Danish beech forest. Agr. Forest. Meteorol., 107(1), 29-41.

853 Pilegaard, K., Ibrom, A., Courtney, M.S., Hummelshøj, P., Jensen, N.O., 2011. Increasing net CO2 uptake by a 854 Danish beech forest during the period from 1996 to 2009. Agr. Forest. Meteorol., 151(7), 934-946.

855 Potter, C.S., Randerson, J.T., Field, C.B., et al., 1993. Terrestrial ecosystem production: a process model based 856 on global satellite and surface data. Global Biogeochem. Cycles, 7(4), 811-841.

857 Rocha, A.V., Su, H.B., Vogel, C.S., Schmid, H.P. Curtis, P.S., 2004. Photosynthetic and water use efficiency 858 responses to diffuse radiation by an aspen-dominated northern hardwood forest. Forest Sci., 50(6), 793-801.

859 Roderick, M.L., Farquhar, G.D., Berry, S.L. and Noble, I.R., 2001. On the direct effect of clouds and 860 atmospheric particles on the productivity and structure of vegetation. Oecologia, 129(1), 21-30.

861 Ross, J., 1976. Radiative transfer in plant communities. In J. L. Monteith (Ed.), Vegetation and the atmosphere 862 (13-56). London: Academic Press.

863 Running, S.W., Nemani, R.R., Heinsch, F.A., Zhao, M., Reeves, M., Hashimoto, H., 2004. A continuous 864 satellite-derived measure of global terrestrial primary production. Bioscience, 54(6), 547-560.

865 Ruimy, A., Kergoat, L., Bondeau, A., Intercomparison, T., Model, P.O.T.P.N., 1999. Comparing global models 866 of terrestrial net primary productivity (NPP): Analysis of differences in light absorption and light use efficiency. 867 Glob. Change Biol., 5(S1), 56-64.

868 Ryu, Y., Baldocchi, D.D., Kobayashi, H., et al., 2011. Integration of MODIS land and atmosphere products with 869 a coupled process model to estimate gross primary productivity and evapotranspiration from $1 \mathrm{~km}$ to global 870 scales. Global Biogeochem. Cycles, 25(4).

871 Saltelli, A., Annoni, P., Azzini, I., Campolongo, F., Ratto, M., Tarantola, S., 2010. Variance based sensitivity 872 analysis of model output. Design and estimator for the total sensitivity index. Comput. Phys. Commun., 181, $873259-270$.

874 Schiermeier, Q., 2006. Oceans cool off in hottest years. Nature 442, 854-855.

875 Sobol, I.M., 2001. Global sensitivity indices for nonlinear mathematical models and their Monte Carlo estimates. 876 Math Comput. Simulat., 55(1), 271-280. 
Spitters, C.J.T., 1986. Separating the diffuse and direct component of global radiation and its implications for 878 modeling canopy photosynthesis Part II. Calculation of canopy photosynthesis. Agr. Forest. Meteorol., 38(1-3), $879 \quad 231-242$.

880

881

882

883

884

885

886

887

888

889

890

891

892

893

894

895

896

897

898

899

900

901

902

903

904

905

906

907

908 909

Steiner, A.L., Chameides, W.L., 2005. Aerosol-induced thermal effects increase modeled terrestrial photosynthesis and transpiration. Tellus B 57 (5), 404-411.

Stroosnijder, L., Moore, D., Alharbi, A., Argaman, E., Biazin, B., van den Elsen, E., 2012. Improving water use efficiency in drylands. Curr. Opin. Environ. Sustain., 4(5), 497-506.

Taylor, K.E., 2001. Summarizing multiple aspects of model performance in a single diagram. J. Geophys. Res.: Atmos., 106(D7), 7183-7192.

Turner, D.P., Urbanski, S., Bremer, D., et al., 2003. A cross-biome comparison of daily light use efficiency for gross primary production. Glob. Change Biol., 9(3), 383-395.

Urban, O., Klem, K., Ač, A., Havránková, K., et al., 2012. Impact of clear and cloudy sky conditions on the vertical distribution of photosynthetic CO2 uptake within a spruce canopy. Funct. Ecol.26 (1), 46-55.

Van de Griend, A.A., Owe, M., 1993. On the relationship between thermal emissivity and the normalized difference vegetation index for natural surfaces. Int. J. Remote Sens., 14(6), 1119-1131.

van Dijk, A.I., Dolman, A.J. Schulze, E.D., 2005. Radiation, temperature, and leaf area explain ecosystem carbon fluxes in boreal and temperate European forests. Global Biogeochem. Cy., 19(2).

Vinukollu, R.K., Meynadier, R., Sheffield, J., Wood, E.F., 2011. Multi-model, multi-sensor estimates of global evapotranspiration: climatology, uncertainties and trends. Hydrol. Process., 25(26), 3993-4010.

Vinukollu, R.K., Wood, E.F., Ferguson, C.R., Fisher, J.B., 2011. Global estimates of evapotranspiration for climate studies using multi-sensor remote sensing data: Evaluation of three process-based approaches. Remote Sens. Environ., 115(3), 801-823.

Wang, S., Huang, K., Yan, H., et al., 2015. Improving the light use efficiency model for simulating terrestrial vegetation gross primary production by the inclusion of diffuse radiation across ecosystems in China. Ecol. Complex., 23, 1-13.

Wang, Y.P., Leuning, R., 1998. A two-leaf model for canopy conductance, photosynthesis and partitioning of available energy I: Model description and comparison with a multi-layered model. Agr. Forest. Meteorol., 91(1), 89-111.

Weiss, S.B. 2000. Vertical and temporal distribution of insolation in gaps in an old-growth coniferous forest. Can. J. For. Res. 30:1953-1964.

Williams, I.N., Riley, W.J., Kueppers, L.M., Biraud, S.C., Torn, M.S., 2016. Separating the effects of phenology and diffuse radiation on gross primary productivity in winter wheat. J. Geophys. Res.: Biogeosci., 121(7), 19031915. 
910 Wu, J., Albert, L. P., Lopes, A. P., et al., 2016. Leaf development and demography explain photosynthetic 911 seasonality in Amazon evergreen forests. Science, 351(6276), 972-976.

912 Wu, J., Linden, L. V. D., Lasslop, G., et al., 2012. Effects of climate variability and functional changes on the 913 interannual variation of the carbon balance in a temperate deciduous forest. Biogeosciences, 9(1), 13-28.

914 Yuan, W., Cai, W., Xia, J., et al., 2014. Global comparison of light use efficiency models for simulating 915 terrestrial vegetation gross primary production based on the LaThuile database. Agr. Forest. Meteorol., 192, 108916120.

917 Zhou, Y., Wu, X., Ju, W., et al., 2015. Global parameterization and validation of a two-leaf light use efficiency 918 model for predicting gross primary production across FLUXNET sites. J. Geophys. Res.: Biogeosci.. 121.4: 919 1045-1072. 